\title{
EphA4 Is Required for Neural Circuits Controlling Skilled Reaching
}

\author{
${ }^{\circ}$ Juan Jiang, ${ }^{1}{ }^{\circledR}$ Klas Kullander, ${ }^{2}$ and Bror Alstermark ${ }^{1 \dagger}$ \\ ${ }^{1}$ Department of Integrative Medical Biology, Section of Physiology, Umeå University, 90187 Umeå, Sweden, and ${ }^{2}$ Developmental Genetics, \\ Department of Neuroscience, Uppsala University, 75124 Uppsala, Sweden
}

Skilled forelimb movements are initiated by feedforward motor commands conveyed by supraspinal motor pathways. The accuracy of reaching and grasping relies on internal feedback pathways that update ongoing motor commands. In mice lacking the axon guidance molecule EphA4, axonal misrouting of the corticospinal tract and spinal interneurons is manifested, leading to a hopping gait in hindlimbs. Moreover, mice with a conditional forebrain deletion of EphA4, display forelimb hopping in adaptive locomotion and exploratory reaching movements. However, it remains unclear how loss of EphA4 signaling disrupts function of forelimb motor circuit and skilled reaching and grasping movements. Here we investigated how neural circuits controlling skilled reaching were affected by the loss of EphA4. Both male and female C57BL/6 wild-type, heterozygous EphA4 $4^{+/-}$, and homozygous EphA4 ${ }^{-/-}$mice were used in behavioral and in vivo electrophysiological investigations. We found that EphA4 knock-out (-/-) mice displayed impaired goal-directed reaching movements. In vivo intracellular recordings from forelimb motor neurons demonstrated increased corticoreticulospinal excitation, decreased direct reticulospinal excitation, and reduced direct propriospinal excitation in EphA4 knock-out mice. Cerebellar surface recordings showed a functional perturbation of the lateral reticular nucleus-cerebellum internal feedback pathway in EphA4 knock-out mice. Together, our findings provide in vivo evidence at the circuit level that loss of EphA4 disrupts the function of both feedforward and feedback motor pathways, resulting in deficits in skilled reaching.

Key words: EphA4; in vivo electrophysiology; mice; neural circuits; propriospinal neurons; skilled reaching

\section{Significance Statement}

The central advances of this study are the demonstration that null mutation in the axon guidance molecule EphA4 gene impairs the ability of mice to perform skilled reaching, and identification of how these behavioral deficits correlates with discrete neurophysiological changes in central motor pathways involved in the control of reaching. Our findings provide in vivo evidence at the circuit level that loss of EphA4 disrupts both feedforward and feedback motor pathways, resulting in deficits in skilled reaching. This analysis of motor circuit function may help to understand the pathophysiological mechanisms underlying movement disorders in humans.

\section{Introduction}

The Eph tyrosine kinase receptors and their ligands, the Ephrins, are important for developmental processes including cell migration, axon guidance, and spatial organization during the development of the CNS (Henkemeyer et al., 1996; Flanagan and Vanderhaeghen, 1998; O'Leary and Wilkinson, 1999; Wegmeyer

\footnotetext{
Received Dec. 4, 2019; revised July 14, 2020; accepted July 20, 2020.

Author contributions: J.J. and B.A. designed research; J.J. and B.A. performed research; J.J. and B.A. analyzed data; J.J. wrote the paper; K.K. discussed and edited the paper.

${ }^{\dagger}$ Deceased, April 5, 2017.

The authors declare no competing financial interests.

This work was supported by Grant 2015-03581 from the Swedish Research Council. We thank E. Azim, T. Isa, L.-G. Pettersson, R. S. Johansson, H. Alstermark, and K.-G. Westberg for comments on the manuscript. We also thank E. Danielsson, P. Utsi, and R. Widmark for technical support.

Correspondence should be addressed to Juan Jiang at juan.jiang@umu.se or jiangjuan2010@gmail.com. https://doi.org/10.1523/JNEUROSCI.2892-19.2020

Copyright $\odot 2020$ the authors
}

et al., 2007; Pasquale, 2008). One member of the EphA receptor family, the EphA4 receptor, is critical for the formation of the corticospinal tract (CST; Dottori et al., 1998; Coonan et al., 2001; Kullander et al., 2001; Butt et al., 2005; Canty et al., 2006), which connects the cerebral cortex to the spinal cord and influences motor neuron (MN) activity. Much work using EphA4-null mutants were directed toward investigating the neural circuits underlying locomotion (Kullander et al., 2003; Butt et al., 2005; Akay et al., 2006; Restrepo et al., 2011; Satoh et al., 2016). Mice that lack EphA4 display a specific motor deficit, a rabbit-like hopping gait in their hindlimbs, which has been ascribed to abnormal bilateral CST projections (Dottori et al., 1998; Coonan et al., 2001) as well as to aberrant midline crossing of excitatory spinal interneurons (INs; Kullander et al., 2003; Borgius et al., 2014). An EphA4 mutation in dorsal Lbxl spinal INs leads to behavioral changes in context-dependent locomotion (Satoh et al., 2016). In EphA4 knock-out mice, abnormal patterns of CST 
projections have been observed in the cervical spinal cord (Dottori et al., 1998; Coonan et al., 2001), where MNs involved in the execution of forelimb movements reside. Recent studies have shown that conditional mutant mice lacking EphA4 in Emx1-expressing CST neurons display abnormal forelimb hopping during adaptive locomotion and exploratory reaching movements (Serradj et al., 2014; Serradj and Martin, 2016). However, it remains unknown how the loss of EphA4 signaling disrupts the development of forelimb motor circuit function and the execution of skilled movements.

Feedforward motor commands for forelimb movements are considered to be mediated by direct CST projections to the spinal cord (Lemon, 2008). Moreover, indirect corticospinal pathways relayed through intermediate projection neurons in the brainstem, including rubrospinal and reticulospinal pathways, are also involved (Alstermark and Isa, 2012). Furthermore, the accuracy of skilled forelimb movements relies on internal feedback pathways that can update ongoing motor commands. Cervical propriospinal neurons (PNs) represent a major internal feedback pathway for forelimb motor commands, displaying ipsilateral dual projections, with one descending branch to forelimb MNs (FMNs; Illert et al., 1977; Alstermark et al., 1990) and one ascending branch to neurons in the lateral reticular nucleus (LRN), a major cerebellar input (Alstermark et al., 1981; Azim et al., 2014; Azim and Alstermark, 2015). Based on this bifurcating output, PNs are thought to transmit an efferent copy of forelimb motor commands directly to the LRN, which in turn transmits this feedback to the cerebellum for online prediction of movement outcome and adjustment of motor output (Alstermark and Isa, 2012; Azim et al., 2014; Pivetta et al., 2014). A subset of excitatory PNs belong to the cardinal V2a IN class (Azim et al., 2014), which expresses EphA4 (Lundfald et al., 2007). However, formation and organization of the PN-LRN-cerebellar internal feedback pathways are poorly understood and need characterization.

In this study, we use behavioral and in vivo electrophysiological techniques to investigate the function of neural circuits controlling reaching in EphA4 knock-out mice. Our work demonstrates that loss of EphA4 results in abnormal neuronal transmission in both descending feedforward command pathways and ascending internal feedback pathways, leading to impaired reaching movements.

\section{Materials and Methods}

\section{Experimental design and statistical analysis}

Animals. The following three groups of male and female adult mice were used: C57BL/6 wild-type, heterozygous EphA4 ${ }^{+-}$, and homozygous EphA $4^{-l-}$ mice. Six wild-type, six $\mathrm{EphA} 4^{+/-}$, and five EphA4 ${ }^{-1-}$ mice were used for goal-directed reaching and grasping tasks. In vivo electrophysiological experiments were performed on 28 male and 13 female mice with body weights of $27.4 \pm 5.2 \mathrm{~g}$. Seven wild-type, seven EphA4 ${ }^{+/-}$, and eight EphA4 ${ }^{-/-}$mice were used for $\mathrm{MN}$ intracellular recordings, and seven wild-type, six EphA4 ${ }^{+/-}$, and six EphA4 ${ }^{-/-}$mice were used for cerebellar surface recordings. Mice were housed with light on a $12 \mathrm{~h}$ light/dark cycle. All experimental procedures were approved by the ethics committee of Umeå University and followed European Union guidelines for animal care.

Statistics. Data analysis was performed with Prism 7 (GraphPad Software). Comparison of the three groups of animals was performed with the $\chi^{2}$ test, paired $t$ test, two-way ANOVA, and Bonferroni post hoc analysis. Data were presented as the mean \pm SEM or the mean \pm $\mathrm{SD}$, and $p<0.05$ was considered statistically significant.

Goal-directed reaching and grasping tasks

The behavioral paradigm was based on previously established methods (Alstermark and Pettersson, 2014b). Mice were trained and tested individually to retrieve sesame seeds in the following three different tasks: (1) work-space test, (2) position test, and (3) lifting-protraction test. Two reach boxes were used (Fig. 1A). Reach box 1 was used for the work-space test and position test. Reach box 2 was used for lifting-protraction test. To ensure motivation to perform the tasks, normal food was removed from the home cages $15 \mathrm{~h}$ before training and testing. Training and tests were conducted every $2-3 \mathrm{~d}$. To record forelimb movements during tests, two digital high-definition video cameras (1080i recording, $100 \mathrm{~Hz}$; Sony) were placed above and to the right of the box $\left(\sim 90^{\circ}\right.$ apart), respectively. The movies were analyzed using Adobe premiere Pro CC.

Work-space test. The mouse was placed into reach box 1, a transparent acrylic test box connected to a cylinder with a 5-mm-wide and 20mm-high slot (Fig. 1A, left). The mouse was trained to retrieve food, through the slot, from a 30-mm-diameter plate covered with sesame seeds (Fig. 1B). Tests began after 15 training sessions. Each session lasted $10 \mathrm{~min}$, after which the mouse was returned to the home cage. The reaching area from which the mice retrieved seeds was analyzed by comparison with the total area of the plate and among the three groups of mice.

Position test. The mouse was placed into reach box 1 and trained to retrieve a single sesame seed in one specific position on the plate within the reaching area. A sesame seed was put at a distance of $10 \mathrm{~mm}$ from the slot, at horizontal angles of $\sim 70^{\circ}, 45^{\circ}$, and $30^{\circ}$, respectively (Fig. $1 C$, positions 1,2 , or 3 ). After 80 training trials, the mouse was tested 100 times across $10 \mathrm{~d}$ in each position (10 times/testing day). Task success was defined as complete reaching and grasping in the first attempt in each trial.

Lifting-protraction test. The mouse was placed into reach box 2 (Fig. $1 A$, right), an acrylic cuboid box with $130 \mathrm{~mm}$ height, $70 \mathrm{~mm}$ width, and $150 \mathrm{~mm}$ length. A block wall with a small slot $(4.5 \mathrm{~mm}$ width, $6 \mathrm{~mm}$ height, and placed $6 \mathrm{~mm}$ above the floor) was positioned at the end of the test box. The mouse was trained to retrieve a single sesame seed placed $10 \mathrm{~mm}$ distal to the slot, at $90^{\circ}$ horizontal angle, on a platform (Fig. 1D). After 180 training trials, the mouse was tested 80 times across $8 \mathrm{~d}$ (10 times/testing day). Task success was defined as complete reaching and grasping in the first attempt in each test.

In vivo electrophysiology

Preparations for the experiments, including anesthesia, tracheotomy, pneumothorax, artificial respiration, laminectomy, and craniotomy, were performed following previously published procedures (Jiang and Alstermark, 2015)

Stimulation. Bulbospinal or corticobulbospinal fibers were stimulated in the ipsilateral and contralateral medial longitudinal fascicle (MLF) or pyramids (Pyr) at $1.0 \mathrm{~mm}$ rostral to obex, $0.45 \mathrm{~mm}$ lateral from the midline, and $0.5-2.3 \mathrm{~mm}$ ventral from the brainstem surface using tungsten electrodes ( $100 \mathrm{~K} \Omega$ impedance) inserted at an angle of $25^{\circ}$ (tip rostral). Similarly, the $\mathrm{LRN}$ was stimulated at $1.3 \mathrm{~mm}$ caudal to obex, $1.3 \mathrm{~mm}$ ipsilateral and contralateral from the midline, and 1.0-1.2 $\mathrm{mm}$ ventral from the brainstem surface. A train of one to three stimuli was given at $300 \mathrm{~Hz}(10-100 \mu \mathrm{A} ; 0.1 \mathrm{~ms}$ pulse duration). The final position of the electrode was adjusted so that descending volleys could be recorded from the surface of the spinal cord, at stimulus intensities $<10$ $\mu \mathrm{A}$. The intensity of $80 \mu \mathrm{A}$ was used as an initial stimulus intensity since the interaction test showed no spreading effect on monosynaptic EPSPs between ipsilateral and contralateral MLF stimulation at $80 \mu \mathrm{A}$ (see Fig. $3 F$ ). The distance between ipsilateral and contralateral electrodes for bilateral MLF or Pyr stimulation was $0.9 \mathrm{~mm}$.

For identification of FMNs, the ipsilateral deep radial (DR) nerve was stimulated by bipolar needle electrodes inserted into forelimb. Constant voltage stimuli ( $0.1 \mathrm{~ms}$ duration) were used, and the intensities were expressed in multiples of threshold $(\mathrm{T})$ for the most sensitive fibers in the nerve. DR stimulation was also used for guidance to antidromically identify the lateral motor nuclei and to assess the physiological integrity of the spinal cord.

Recording. Intracellular recordings were made with borosilicate glass microelectrodes (15-30 M $\Omega$ impedance) filled with $2 \mathrm{M}$ potassium citrate, $\mathrm{pH}$ 7.4, from $276 \mathrm{DR}$ MNs (identified by antidromic activation 
A $\quad$ Reach box 1

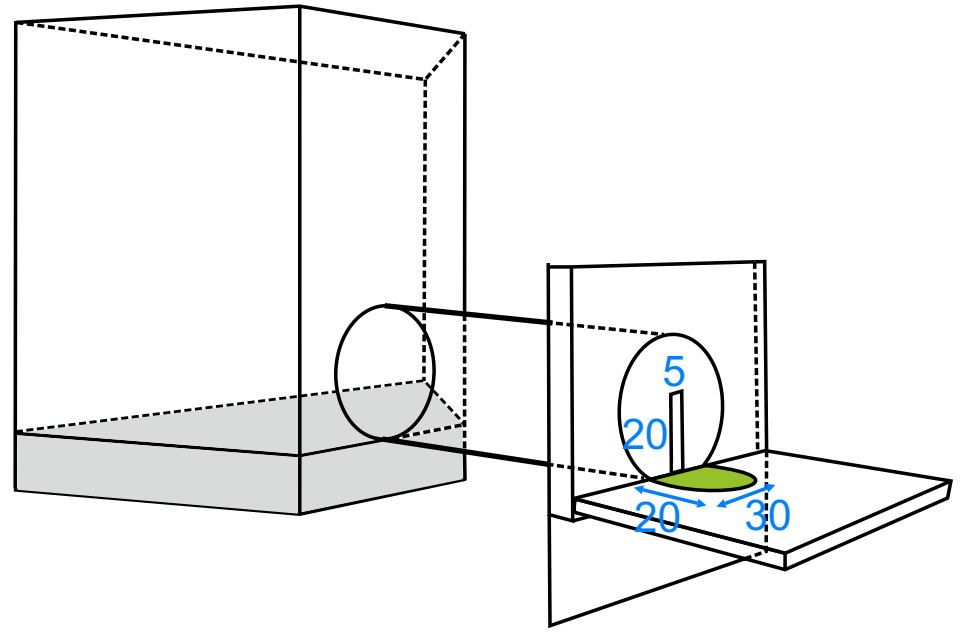

Reach box 2

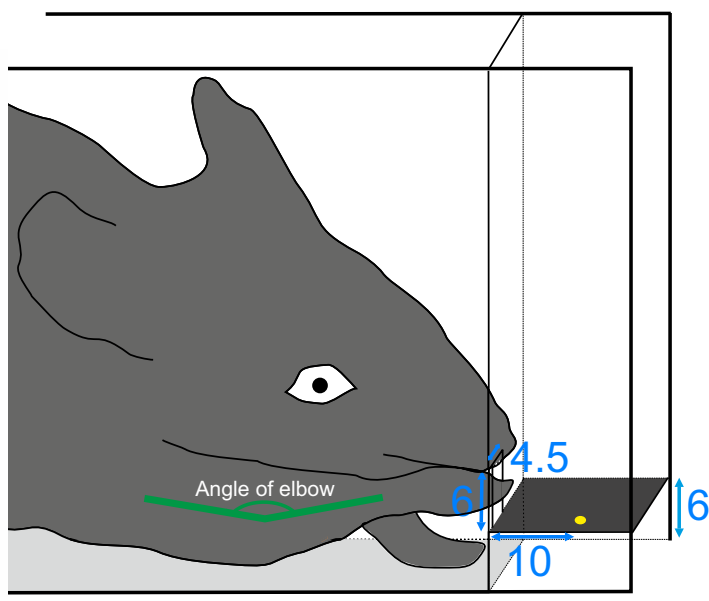

B Work-space test

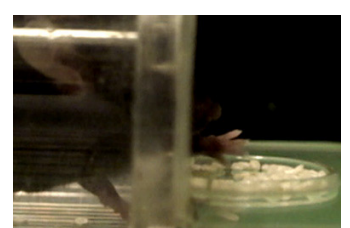

Wild-type EphA4+/- EphA4-/-

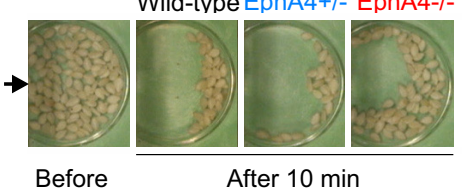

Work-space test

Reaching area (\%)

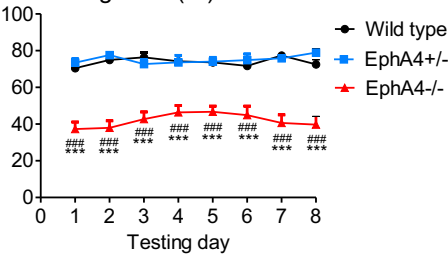

C
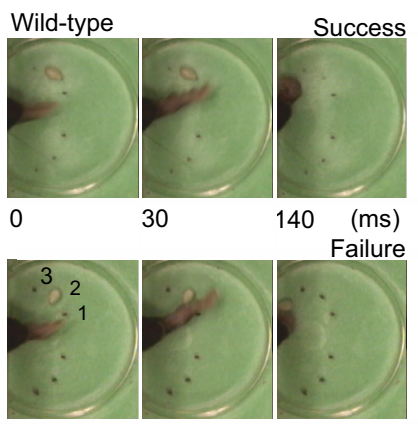

0

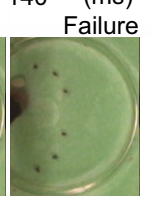

180
Position 1 test

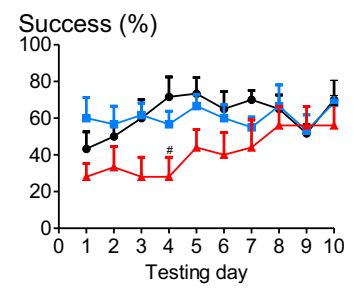

Position test
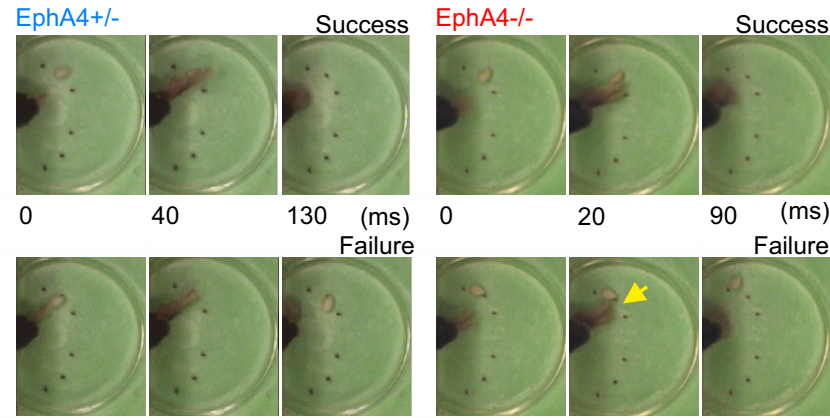

30

130

(ms) 0

20

$80 \quad(\mathrm{~ms})$

osition 2 test

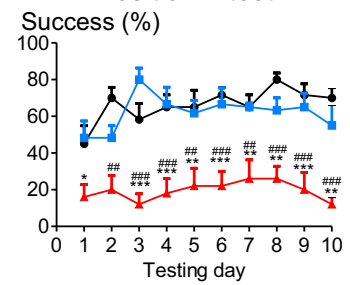

Position 3 test Success (\%)

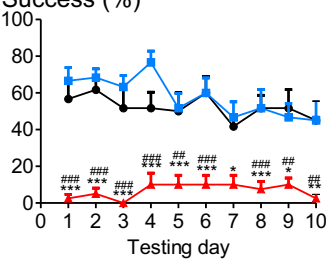

D

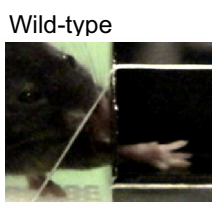

90

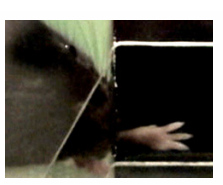

60

\section{Lifting-protraction test}

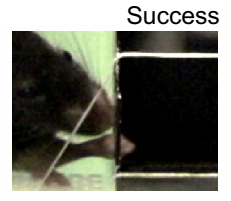

170

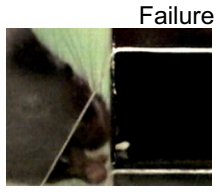

(ms) 100

80

210
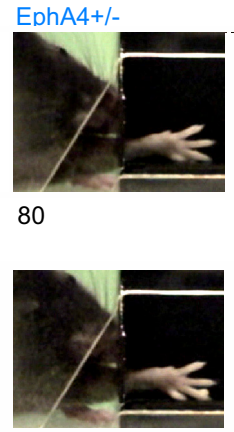

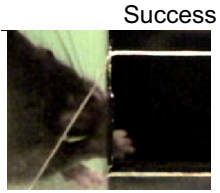

180

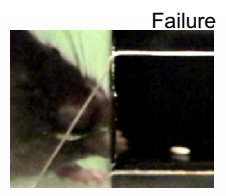

200

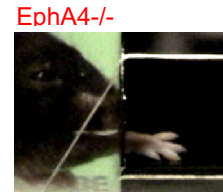

80

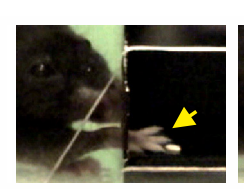

120

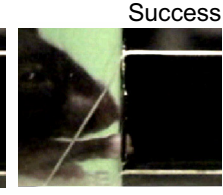

(ms)
Failure

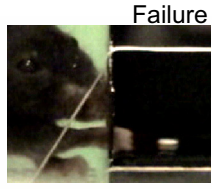

(ms)

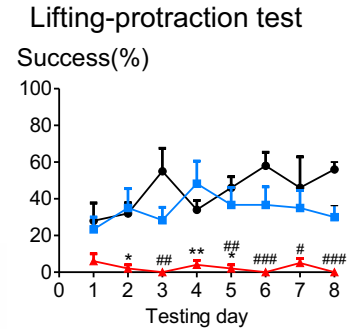

150

Figure 1. EphA4 knock-out mice display impairment in reach-to-grasp movements. $\boldsymbol{A}$, Schematic drawing of reach boxes 1 and 2 (oblique lateral view; measurements in millimeters). Reach box 1 was used for the work-space test and position test. Reaching box 2 was used for the lifting-protraction test. Angle of elbow indicates the angle at the elbow when the mouse propelled the paw into the slot. The yellow point shows the location of a single sesame seed that was placed $10 \mathrm{~mm}$ away from the slot with $90^{\circ}$ horizontal angle. $\boldsymbol{B}$, Work-space test (side view, top); reaching area before and after $10 \mathrm{~min}$ of forelimb movements (top view, middle); comparison of reaching area showed a smaller reaching range in EphA4 ${ }^{-1-}$ mice (bottom). Two-way 
from the DR nerve). We also included 48 unidentified MNs recorded in the same tracks as the DR MNs. Cord dorsum potentials were recorded with a silver ball electrode on the surface of the dorsal column (DC) in the middle part of the C6-C7 segments (at the level of the microelectrode penetrations) to monitor the incoming volley. Cerebellar surface recordings were made with a silver ball electrode on the cerebellar surface at 36 positions (see Fig. 7A). Good physiological conditions of the animals could be maintained for 3-5 h following surgery.

Data acquisition. Data were acquired using a Digidata 1200 digitizer and pClamp software, and were analyzed offline with Clampfit (Molecular Devices). Excitatory and inhibitory postsynaptic potentials were intracellularly recorded from $\mathrm{MNs}$ by stimulating the ipsilateral and contralateral MLF, pyramids, and LRN. In case of cerebellar surface recordings, the direct (N1) and synaptic (N2) potentials were evoked by stimulation in the ipsilateral LRN. After each experiment, the stimulation and recording sites and the ipsilateral C1/C2 hemisection were verified histologically. Only data obtained in experiments in which the electrodes were appropriately placed were analyzed.

\section{Results}

EphA4 knock-out mice display impaired reaching

To investigate how EphA4 knock-out $(-/-)$ mice perform skilled reaching and grasping behavior, we recorded forelimb movements in wild-type mice $(n=6)$; heterozygous EphA $4^{+/-}$ mice $(n=6)$, which show a normal alternating gait; and homozygous EphA4 $4^{-l-}$ mice $(n=5)$, which display a defective hopping gait (Dottori et al., 1998; Kullander et al., 2001; Akay et al., 2006). Mice were trained to retrieve food in the following three different tasks with gradually increasing demands on spatial accuracy: (1) work-space test, which has no restriction on food location; (2) position test, which has a spatial restriction on food location; (3) lifting-protraction test, which has a high restriction of work space.

In the work-space test, mice were placed individually in reach box 1 (Fig. 1A, left), where they could reach out and retrieve food through a slot from a 30-mm-diameter dish covered with sesame seeds. The area from which mice reached and removed food was analyzed and compared with the total area of the dish. As shown in Figure $1 B$, the reaching area clearly differed across the three groups of mice (two-way ANOVA: $F_{(2,110)}=322.2$; $p<0.0001)$. The average reaching area for EphA $4^{-1-}$ mice $(42.0 \pm 8.9 \%$ of total area, mean $\pm \mathrm{SD})$ was considerably smaller than for wild-type mice $\left(73.9 \pm 5.5 \%\right.$ of total area) and EphA $4^{+/-}$ mice $(75.2 \pm 5.6 \%$ of total area).

In the position test, mice were presented with a single sesame seed located in one of three positions within their reaching area (Fig. 1C). Performance was quantified as the frequency of successful retrievals, which was defined as complete reaching and grasping in the first attempt of each test. The success rate was overall lower in EphA4 $4^{-1-}$ mice than in other two groups (two-

\footnotetext{
$\leftarrow$

ANOVA, $F_{(2,110)}=322.2 ; p<0.0001$. C, Success and failure of reaching and grasping in the position test (top view: top and middle). EphA4 ${ }^{-1-}$ mice showed a lower success rate than in the other two groups, especially at positions 2 and 3 (bottom). Two-way ANOVA: position 1, $F_{(2,138)}=14.1, p<0.0001$; position 2, $F_{(2,138)}=106.1, p<0.0001$; position 3, $F_{(2,138)}=126.9, p<0.0001$. $D$, Success and failure of reaching and grasping in the liftingprotraction test (left). EphA4 ${ }^{-1-}$ mice showed a lower success rate in reaching and grasping (right). Success, complete reaching and grasping; failure, incomplete reaching or reaching but inability to grasp sesame seeds. Two-way ANOVA: $F_{(2,96)}=46.3, p<0.0001$. The yellow arrows in $\boldsymbol{B}$ and $\boldsymbol{C}$ indicate hypometria during reaching movement in $\mathrm{EphA}^{-1-}$ mice. Video recordings sampled at $100 \mathrm{~Hz}$. Date are represented as the mean \pm SEM; $n=5-6$ mice/ group. Post hoc Bonferroni test: $\# p<0.05$, \#\#p $<0.01$, \#\#\# $<0.0001$ versus wild-type mice; ${ }^{*} p<0.05,{ }^{* *} p<0.01,{ }^{* * *} p<0.0001$ versus $\mathrm{EphA4}^{+/-}$mice.
}

Table 1. The average success rate for $\mathrm{EphA4}^{-1-}$ mice is significantly lower than for wild-type or EphA4 ${ }^{+/-}$mice in positions 2 and 3 tests and the lifting-protraction test

\begin{tabular}{lllll}
\hline & \multicolumn{2}{l}{ Position test } & & \\
\cline { 2 - 4 } Mice & Position 1 & Position 2 & Position 3 & Lifting-protraction \\
test
\end{tabular}

Data are represented as the mean \pm SD.

${ }^{a}$ The average success rate is analyzed from three $\mathrm{EphA4}^{-/-}$mice. The other two EphA4 ${ }^{-1-}$ mice could not perform the lifting-protraction test.

way ANOVA: position 1, $F_{(2,138)}=14.1, p<0.0001$; position 2, $F_{(2,138)}=106.1, p<0.0001$; position $\left.3, F_{(2,138)}=126.9, p<0.0001\right)$. This difference was mainly accounted for by a weaker performance in lateral positions 2 and 3 (Fig. 1C, bottom, Table 1). The results suggest that reach-to-grasp movements were perturbed in EphA4 knock-out mice, especially at lateral positions when the demands on spatial accuracy are high.

In the lifting-protraction test, performed in reaching box 2 (Fig. $1 A$, right), we increased the difficulty of the task by positioning a sesame seed $10 \mathrm{~mm}$ away from a smaller and higher slot, so that reaching requires combined lifting and protraction movements. First attempt success rates showed that the performance differed across the groups of mice. The success rate for EphA4 $4^{-1-}$ mice was far lower than that for wild-type or EphA $4^{+/-}$mice (two-way ANOVA: $F_{(2,96)}=46.3 ; p<0.0001$; Fig. $1 D$, right, Table 1). Moreover, two EphA $4^{-1-}$ mice were never able to perform the task.

These results indicate that reach-to-grasp movements are impaired in EphA4 $4^{-1-}$ mice. To further explore what defects may underlie the observed failures, we analyzed the proportion of failures that occurred in the reaching or grasping phase. As shown in Figure $2 A$, the proportion of failures during the reaching phase was much higher in EphA4 $4^{-/-}$mice than in wild-type and EphA4 ${ }^{+/-}$mice (two-way ANOVA: position 1 test, $F_{(2,138)}=9.2$, $p=0.0002$; position 2 test, $F_{(2,138)}=14.3, p<0.0001$; position 3 test, $F_{(2,138)}=25.1, p<0.0001$; lifting-protraction test, $F_{(2,96)}=58.3$, $p<0.0001)$. The differences were most clear in the position 3 test and the lifting-protraction test. However, no significant difference was found in the proportion of failures during the grasping phase in the position 1 test and position 3 test among the three groups of mice. The proportion of failures in grasping was higher in the position 2 test but was lower in the lifting-protraction test in EphA $4^{-1-}$ mice than in wild-type and EphA $4^{+/-}$mice (two-way ANOVA: position 1 test, $F_{(2,150)}=2.7, p=0.07$; position 2 test, $F_{(2,150)}=15.3, p<0.0001$; position 3 test, $F_{(2,150)}=3.0, p=0.05$; lifting-protraction test, $\left.F_{(2,97)}=7.5, p=0.0009\right)$.

These results suggest that food retrieval failures in EphA4 $4^{-1-}$ mice were mainly because of deficits in reaching. The EphA $4^{-1-}$ mice displayed hypometria during reaching (Fig. $1 C, D$, yellow arrows) or failed to direct the unilateral paw through the slot. Analysis of the orientation angle of the paw for reaching movements to positions 1 and 3 revealed that EphA $4^{-1-}$ mice showed large initial reaching and withdraw angles (Fig. $2 B$ ), indicating misdirection with a larger distance between the paw and the target compared with wild-type and EphA $4^{+/-}$mice (two-way ANOVA; initial reaching angle: position 1 test, $F_{(2,139)}=55.6$, $p<0.0001$; position 3 test, $F_{(2,139)}=79.3, p<0.0001$; angle between paw and target: position $1, F_{(2,139)}=22.2, p<0.0001$; position 3 test, $\left.F_{(2,139)}=62.3, p<0.0001\right)$. Moreover, in the lifting-protraction test, EphA $4^{-1-}$ mice showed higher elevation of 
A
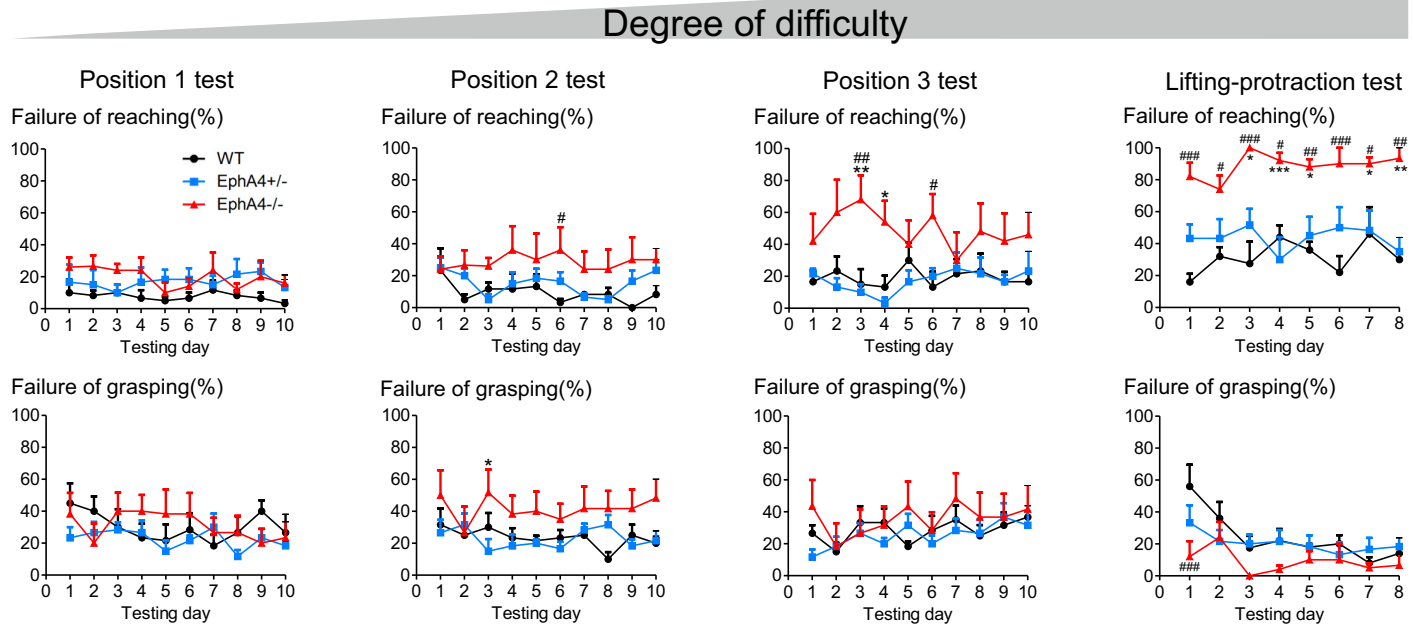

B

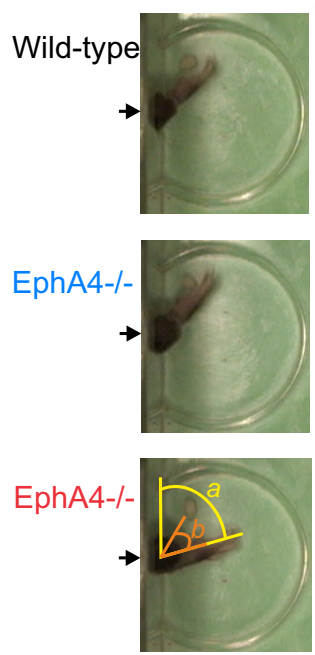

Position 1 test

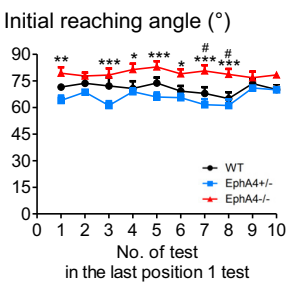

Angle between paw and target $\left({ }^{\circ}\right)$

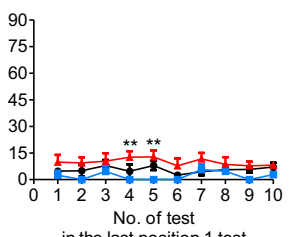

\section{Position 3 test}

Initial reaching angle $\left(^{\circ}\right)$
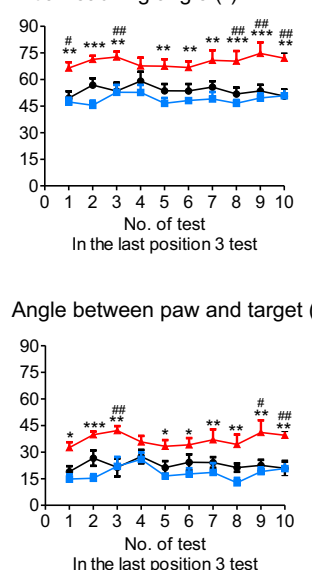

C

\section{Lifting-protraction test}
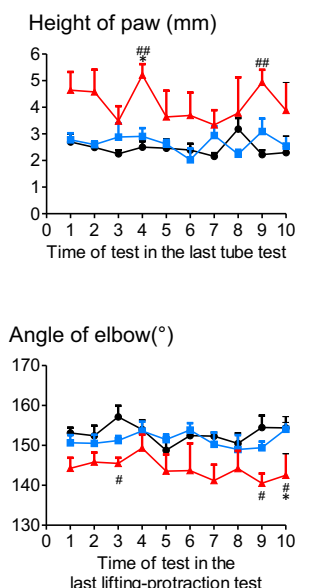

Figure 2. EphA4 knock-out mice display major impairment in reaching, but not in grasping. $\boldsymbol{A}$, EphA4${ }^{-1-}$ mice showed major proportion of failures in reaching phase, but not in grasping phase. No significant difference in failures of grasping in the position 1 and position 3 tests among three groups of mice. With increased task difficulty, EphA4 ${ }^{-1-}$ mice showed increased failures in reaching phase. The gray triangle bar indicates the degree of task difficulty. Two-way ANOVA; failure of reaching: position 1 test, $F_{(2,138)}=9.2, p=0.0002$; position 2 test, $F_{(2,138)}=14.3, p<0.0001$; position 3 test, $F_{(2,138)}=25.1, p<0.0001$; lifting-protraction test, $F_{(2,96)}=58.3, p<0.0001$; failure of grasping: position 1 test, $F_{(2,150)}=2.7, p=0.07 ;$ position 2 test, $F_{(2,150)}=15.3, p<0.0001$; position 3 test, $F_{(2,150)}=3.0, p=0.05$; lifting-protraction test, $F_{(2,97)}=7.5, p=0.0009$. $B$, Analysis of initial reaching angle (a) and angle between paw and target (b) in position 1 and position 3 tests. EphA4 ${ }^{-1-}$ mice showed large initial reaching angle and angle between paw and target. Two-way ANOVA; initial reaching angle: position 1 test, $F_{(2,139)}=55.6, p<0.0001$; position 3 test, $F_{(2,139)}=79.3, p<0.0001$; angle between paw and target: position $1, F_{(2,139)}=22.2, p<0.0001 ;$ position 3 test, $F_{(2,139)}=62.3, p<0.0001$. $C$, EphA4 ${ }^{-1-}$ mice showed high elevation of paw and small angle of elbow when entering into the slot in the lifting-protraction test. Two-way ANOVA: height of paw, $F_{(2,177)}=28.0$, $p<0.0001$; angle of elbow, $F_{(2,117)}=27.0, p<0.0001$. Data are represented as the mean \pm SEM; $n=5-6$ mice/group. Post hoc Bonferroni test: \#p $<0.05$, \#\#p $<0.01$, \#\#\# $<0.0001$ versus wild-type; ${ }^{*} p<0.05,{ }^{* *} p<0.01,{ }^{* * *} p<0.0001$ versus EphA4 ${ }^{+/-}$.

the paw and smaller angles at the elbow when propelling the paw into the slot (Fig. $2 \mathrm{C}$ ), causing failure to reach the target (twoway ANOVA: height of paw, $F_{(2,117)}=28.0, p<0.0001$; angle of elbow, $\left.F_{(2,117)}=27.0, p<0.0001\right)$. In addition, the knock-out mice displayed forelimb hopping movement in the lifting-protraction test. They lifted left and right forelimbs simultaneously when they tried to move digits to the target. They also landed with both forelimbs simultaneously. The occurrence of the forelimb hopping is between $10 \%$ and $70 \%$ in five EphA4 knock-out mice, making it impossible to guide the paw through the slot and reach the target.

Together, these behavioral studies demonstrate that loss of EphA4 function results in poor spatial precision mainly in goaldirected reaching movements, suggesting a selective deficit in motor circuits that control reaching.

\section{Loss of EphA4 disrupts function of feedforward motor pathways implicated in the control of reaching}

To investigate whether the reaching deficit in EphA $4^{-1-}$ mice is associated with distinguishable abnormalities in neural circuits controlling reaching, we examined the synaptic effects evoked from three descending pathways transmitting feedforward motor commands to FMNs.

\section{Decreased monosynaptic reticulospinal excitation on FMNs in} EphA4 knock-out mice

It has been suggested that reticulospinal tracts (ReSTs) provide strong excitatory input to FMNs in the mouse (Alstermark and Ogawa, 2004). To investigate effects from the ReSTs in EphA4 knock-out mice, we performed in vivo intracellular recordings from FMNs (wild-type, $n=63$; EphA $4^{+/-}, n=48$; EphA $4^{-l-}$, 
A A
Wild-type

EphA4+/-

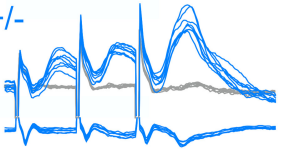

EphA4-/-
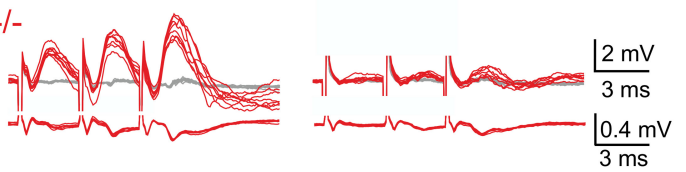

B

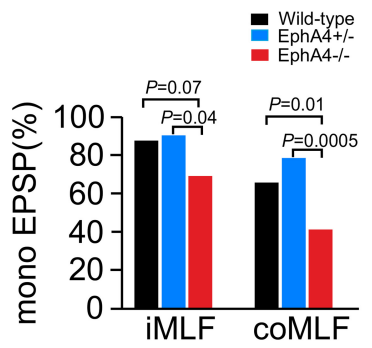

C
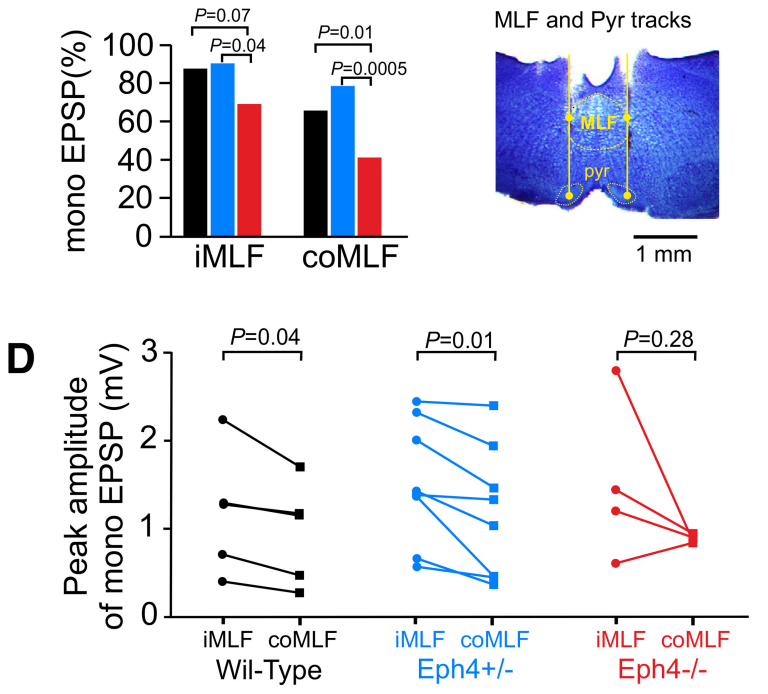

E
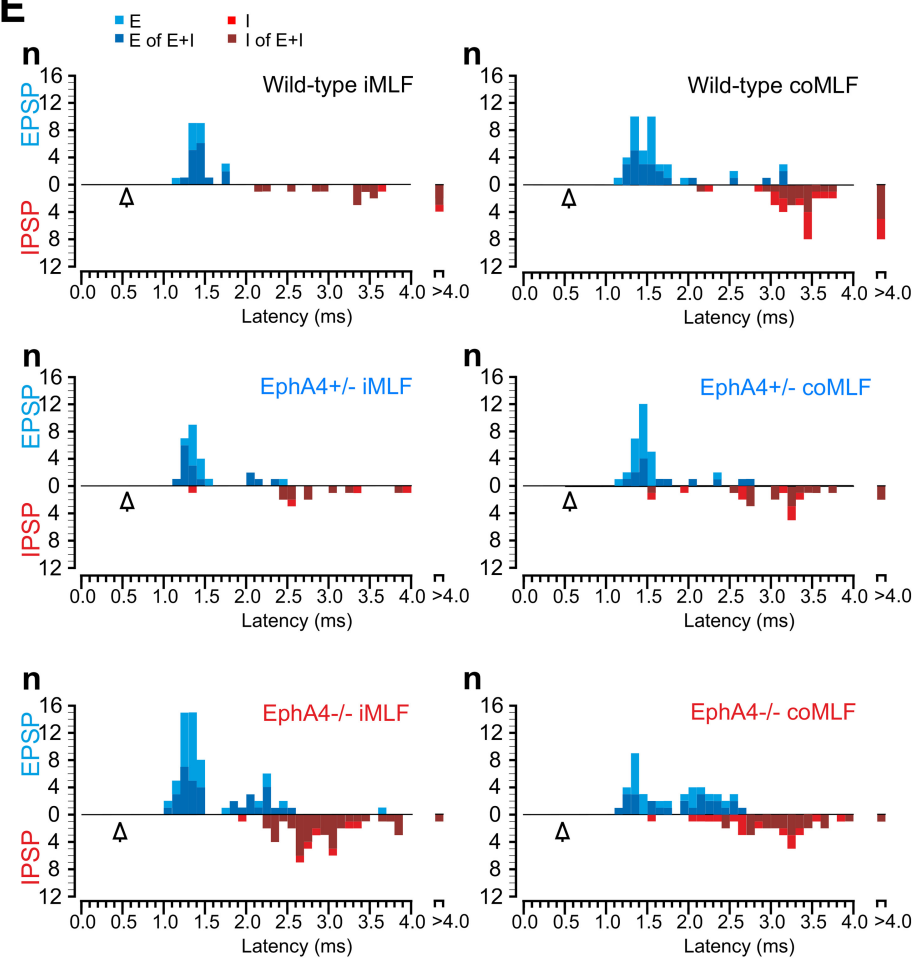

$\mathbf{F}$

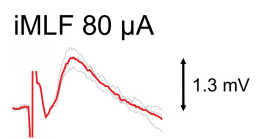

CoMLF $80 \mu \mathrm{A}$

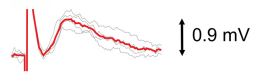
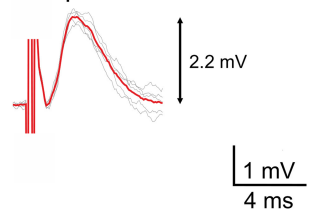

Figure 3. Direct reticulospinal excitation of forelimb motor neurons is reduced in EphA4 knock-out mice. $A$, Samples of EPSPs evoked by stimulation of ipsilateral and contralateral MLF in forelimb motor neurons in wild-type (black), EphA4 ${ }^{+-}$(blue), and EphA4 ${ }^{-1-}$ (red) mice. IC, intracellular recordings; EC, extracellular recordings (gray lines); (DP, cord dorsum potential. $80 \mu \mathrm{A} \times 3$, stimulation intensity with a train of 3 stimuli at $80 \mu \mathrm{A}$. B. Comparison of proportions of monosynaptic EPSPs in three groups of mice. $\chi^{2}$ test: ipsilateral (ipsi), $\chi^{2}(2$, $n=109)=6.4, p=0.04$; contralateral (contra), $\chi^{2}(2, n=113)=13.6, p=0.001$. C, A transverse section shows ipsilateral and contralateral MLF and Pyr tracks for electrical stimulation. $\boldsymbol{D}$, Comparison of peak amplitude of monosynaptic EPSPs evoked by stimulation of iMLF and coMLF in same MNs. $E$, Segmental latencies of EPSPs and IPSPs in each group. Empty triangle shows the latency of the direct volley. $\boldsymbol{F}$, Summation of monosynaptic EPSPs evoked by stimulation of iMLF and coMLF in a same EphA4 ${ }^{-I-}$ MN suggested that there was no spreading effect with the intensity of $80 \mu \mathrm{A}$. Red lines show the average of three to five sweeps of EPSPs (black lines).

$n=92$ ) and evoked postsynaptic potentials by electrical stimulation of the bulbospinal pathway in the ipsilateral and contralateral MLF (Auclair et al., 1999; Jiang and Alstermark, 2015; Fig. $3 A$ ). EPSPs, IPSPs, and mixed responses (EPSPs + IPSPs) could be observed, and no significant difference was found in the proportions of EPSPs, IPSPs, and mixed responses in the three groups of mice (Table 2).

Nevertheless, for neurons showing EPSPs, monosynaptic excitation was less frequent in EphA $4^{-1-}$ mice than in wild-type and EphA $4^{+/-}$mice following both ipsilateral and contralateral MLF stimulation [ $\chi^{2}$ test: ipsilateral, $X^{2}(2, n=109)=6.4, p=$ 0.04 ; contralateral, $X^{2}(2, n=113)=13.6, p=0.001$; Fig. $\left.3 B\right]$. In wild-type mice, monosynaptic EPSPs elicited by stimulation in the ipsilateral MLF (iMLF EPSPs) were evoked in 87.0\% (20 of 23) of MNs and monosynaptic EPSPs evoked by stimulation in the contralateral MLF (coMLF EPSPs) were found in $64.1 \%$ (25 of 39) of MNs. Similar results were observed in EphA $4^{+/-}$mice; monosynaptic iMLF EPSPs and coMLF EPSPs were evoked in $90.5 \%$ (19 of 21 ) and $78.6 \%$ (22 of 28 ) of MNs, respectively. In
EphA $4^{-1-}$ mice, $67.7 \%$ (44 of 65) of FMNs showed monosynaptic iMLF EPSPs, which was significantly decreased compared with EphA4 ${ }^{+/-}$mice $\left[\chi^{2}\right.$ test: $\left.X^{2}(1, n=86)=4.2, p=0.04\right]$, but not compared with wild-type mice $\left[\chi^{2}\right.$ test: $X^{2}(1, n=88)=3.2$, $p=0.07]$. Moreover, stimulation of coMLF only evoked monosynaptic EPSPs on $37.0 \%$ (17 of 46 ) of MNs, which was significantly lower than one from wild-type $\left[\chi^{2}\right.$ test: $X^{2}(1, n=$ $85)=6.2, p=0.01]$ and EphA $4^{+/-}\left[\chi^{2}\right.$ test: $X^{2}(1, n=74)=$ $12.1, p=0.0005]$. These results show that the occurrence of monosynaptic MLF EPSPs, especially of monosynaptic coMLF EPSPs, on FMNs was decreased in EphA4 knockout mice.

In addition, we analyzed the peak amplitude of monosynaptic iMLF and coMLF EPSPs recorded in the same MNs (Fig. 3D). To eliminate the influence of membrane potentials on the magnitude of EPSPs, only the MNs in which membrane potentials were relatively stable during recordings were analyzed. The result shows a significant difference between the peak amplitude of iMLF and coMLF monosynaptic EPSPs on FMNs from wild- 
Table 2. Proportion of EPSP, IPSP, and mixed responses evoked by stimulation in the Pyr, MLF and LRN in FMNs from wild-type, EphA4 ${ }^{+/-}$, and EphA4 ${ }^{-/-}$mice

\begin{tabular}{|c|c|c|c|c|c|}
\hline Mice & iPyr & coPyr & iMLF & coMLF & iLRN \\
\hline \multicolumn{6}{|l|}{ Wild-type } \\
\hline EPSP & $66.7 \%$ (4 of 6 ) & $36.4 \%$ (12 of 33 ) & $38.5 \%$ (10 of 26$)$ & $36.1 \%$ (22 of 61$)$ & $26.9 \%$ (18 of 67 ) \\
\hline IPSP & $16.7 \%$ (1 of 6 ) & $42.4 \%$ (14 of 33 ) & $7.7 \%$ (2 of 26$)$ & $27.9 \%$ (17 of 61$)$ & $13.4 \%$ (9 of 67 ) \\
\hline$E+I$ & $16.7 \%$ (1 of 6 ) & $21.2 \%$ (7 of 33$)$ & $53.8 \%$ (14 of 26$)$ & $36.1 \%(22$ of 61$)$ & $59.7 \%$ (40 of 67 ) \\
\hline \multicolumn{6}{|l|}{$\mathrm{EphA4}^{+/-}$} \\
\hline EPSP & $52.4 \%$ (11 of 21$)$ & $34.3 \%$ (12 of 35$)$ & $51.7 \%$ (15 of 29$)$ & $40.5 \%$ (15 of 37$)$ & $22.5 \%$ (9 of 40 ) \\
\hline IPSP & $42.9 \%$ (9 of 21$)$ & $42.9 \%$ (15 of 35$)$ & $13.8 \%$ (4 of 29 ) & $18.9 \%$ (7 of 37$)$ & $5.0 \%(2$ of 40$)$ \\
\hline$E+I$ & $4.8 \%$ (1 of 21$)$ & $22.9 \%$ (8 of 35 ) & $34.5 \%$ (10 of 29$)$ & $40.5 \%$ (15 of 37$)$ & $72.5 \%$ (29 of 40$)$ \\
\hline \multicolumn{6}{|l|}{ EphA4 ${ }^{-1-}$} \\
\hline EPSP & $52.5 \%(21$ of 40$)$ & $38.8 \%$ (19 of 49$)$ & $34.7 \%(25$ of 72$)$ & $39.7 \%(25$ of 63$)$ & $38.6 \%$ (32 of 83 ) \\
\hline IPSP & $20.0 \%$ (8 of 40 ) & $28.6 \%$ (14 of 49$)$ & $9.7 \%$ (7 of 72$)$ & $27.0 \%$ (17 of 63 ) & $13.3 \%$ (11 of 83 ) \\
\hline$E+I$ & $27.5 \%$ (11 of 40 ) & $32.6 \%$ (16 of 49$)$ & $55.6 \%$ (40 of 72$)$ & $33.3 \%$ (21 of 63$)$ & $48.2 \%$ (40 of 83 ) \\
\hline
\end{tabular}

$\mathrm{E}+\mathrm{I}$, Mixed EPSP and IPSP; iLRN, stimulation in the propriospinal neuron ascending axonal branch in the ipsilateral LRN.

type (iMLF, $1.2 \pm 0.7 \mathrm{mV}$; coMLF, $1.0 \pm 0.6 \mathrm{mV}$; mean $\pm \mathrm{SD}$, $n=5$; paired $t$ test, $p=0.04$ ) and from EphA4 ${ }^{+/-}$mice (iMLF, $1.5 \pm 0.7 \mathrm{mV}$; coMLF, $1.2 \pm 0.8 \mathrm{mV}$; mean $\pm \mathrm{SD}, n=8$; paired $t$ test, $p=0.01)$. However, there was no such difference from EphA $4^{-1-}$ mice (iMLF, $1.5 \pm 0.9 \mathrm{mV}$; coMLF, $0.9 \pm 0.1 \mathrm{mV}$; mean $\pm \mathrm{SD}, n=4$; paired $t$ test, $p=0.28)$. These results suggest that lack of EphA4 appears to disturb direct monosynaptic transmission of feedforward motor commands from reticulospinal neurons to FMNs and, in particular, to contralateral FMNs.

\section{Increased MN excitation by corticospinal tract stimulation in} EphA4 knock-out mice

Cortical excitation on FMNs evoked by pyramidal stimulation is weak and nonmonosynaptic in the mouse (Alstermark and Ogawa, 2004). To investigate effects from corticofugal pathways in EphA4 knock-out mice, we performed in vivo intracellular recordings from FMNs (wild-type, $n=33$; $\mathrm{EphA}^{+/-}, n=40$; EphA $4^{-l-}, n=60$ ) and evoked postsynaptic potentials by stimulation in the ipsilateral pyramids (iPyr) and contralateral pyramids (coPyr). As with MLF stimulation, EPSPs, IPSPs, and mixed responses could be evoked by pyramidal stimulation, and no significant differences were observed in the proportions of EPSPs, IPSPs, and mixed responses in the three groups of mice (Table 2). However, iPyr and coPyr stimulation could elicit large EPSPs in EphA4 $4^{-1-}$ mice compared with wild-type and EphA $4^{+/-}$mice (Fig. $4 A$ ). In EphA4 ${ }^{-1-}$ mice, $50 \%$ (8 of 16) of MNs showed large EPSPs (peak amplitude of EPSPs, $>4 \mathrm{mV}$ ) or action potentials with coPyr stimulation intensity at $80 \mu \mathrm{A}$ with a train of two stimuli, which is rarely observed in wild-type mice ( 1 of $16 \mathrm{MNs}$ ) and EphA4 ${ }^{+/-}$mice [0 of $13 \mathrm{MNs} ; \chi^{2}$ test: $X^{2}(2$, $n=45)=14.1, \quad p=0.0008$; wild-type vs EphA4 ${ }^{+/-}, X^{2}(1$, $n=29)=0.8, p=0.36$; wild-type vs EphA4 ${ }^{-1-}, X^{2}(1, n=32)=7.6$, $p=0.0008$; EphA4 ${ }^{+/-}$vs EphA4 $\left.{ }^{-1-}, X^{2}(1, n=29)=9.0, p=0.003\right]$. Such large EPSPs or action potentials evoked by iPyr stimulation were also observed in 6 of $17 \mathrm{MNs}$ from EphA $4^{-1-}$ mice, but not in MNs from wild-type and EphA $4^{+/-}$mice [wild-type mice, 0 of 5 ; EphA4 ${ }^{+/-}$mice, 0 of 6 ; EphA4 ${ }^{-1-}$ mice, 6 of $17 ; \chi^{2}$ test: $X^{2}(2$, $n=28)=4.9, p=0.08]$. These data suggest that synaptic efficacy from corticospinal neurons to MNs, especially contralateral MNs, is increased in EphA4 ${ }^{-/-}$mice.

As in control mice, no monosynaptic EPSPs were observed in EphA $4^{-l-}$ mice as judged by the latencies measured from the effective stimulation to the onset of EPSPs (range, between 2.3 and $5.0 \mathrm{~ms}$; Fig. 4B). These data suggest that the increased synaptic recruitment from corticospinal neurons to FMNs in EphA4null mutants is relayed by other neurons, such as interneurons and reticulospinal neurons.
Cortical excitation on FMNs is drastically reduced after ipsilateral ReST lesion

To determine whether the increased cortical excitation on FMNs was mediated via the corticoreticulospinal tract (CRST) or the CST in EphA4 $4^{-1-}$ mice, we performed an ipsilateral C1/C2 hemisection to lesion the ReST (Watson and Harrison, 2012; Fig. 5). To maintain the integrity of the CST, the dorsal column (DC) was spared (Dottori et al., 1998).

We first tested whether the lesion could block reticulospinal excitation on FMNs. After the lesion, monosynaptic iMLF and coMLF EPSPs disappeared in all tested MNs (wild type, $n=23$; EphA $4^{+/-}, n=28$; EphA $4^{-/-}, n=17$; Fig. $5 B$, top), confirming that the direct excitation on FMNs was mediated via the bilateral ReST. This suggests that the contralateral ReSTs cross the midline mainly before the $\mathrm{C} 1 / \mathrm{C} 2$ cervical spinal cord level and project directly to ipsilateral FMNs (Fig. 5C). However, small nonmonosynaptic coMLF EPSPs could still be evoked in $73.9 \%$ (17 of 23 ), $85.7 \%$ (24 of 28 ), and $64.7 \%$ ( 11 of 17 ) of MNs from wild-type, EphA4 $4^{+/-}$, and EphA4 $4^{-1-}$ mice, respectively. The peak amplitudes of coMLF EPSP were $0.6 \pm 0.3$, $0.4 \pm 0.2$, and $0.5 \pm 0.3 \mathrm{mV}$ (mean $\pm \mathrm{SD}$ ) in wild-type, EphA4 ${ }^{+/-}$, and EphA4 ${ }^{-1-}$ mice, respectively. The latencies of EPSPs measured from the direct MLF volley ranged between 1.1 and $3.5 \mathrm{~ms}$. These remaining small coMLF EPSPs after the lesion might be mediated via some few contralateral ReSTs crossing the midline in the more caudal cervical spinal cord and activating ipsilateral $\mathrm{MNs}$ via INs (Fig. $5 \mathrm{C}$, number 3 ). These data indicate that the lesion blocked direct reticulospinal excitation on FMNs in EphA $4^{-1-}$ mice, as it also did in wild-type and EphA $4^{+/-}$mice.

We next tested whether the lesion would also block cortical excitation on FMNs. After lesioning, iPyr-induced EPSPs disappeared (Fig. 5B, left bottom), potentially suggesting that the ipsilateral component of the CST contributed to this excitation. However, the uncrossed CST is not known to terminate on MNs in rodents (Brösamle and Schwab, 1997), and that is why we consider this possibility less likely. On the other hand, stimulation of coPyr could still evoke very small polysynaptic EPSPs in $85.0 \%$ (17 of 20) of the MNs (Fig. $5 B$, right bottom). The range of latencies of coPyr EPSPs was between 2.3 and $2.7 \mathrm{~ms}$, and the peak amplitudes were $0.6 \pm 0.3 \mathrm{mV}(n=17)$. The remaining small coPyr EPSPs might be mediated by abnormally crossed CSTs and INs (Fig. $5 C$, nos. 1, 2) or share the same mechanism as the remaining small coMLF after the lesion (Fig. 5C, no. 3).

Together, these data suggest that the observed increase of cortical excitatory coupling to FMNs in EphA4-null mutant mice was mediated by the CRST, but not the CST. 
A

iPyr $80 \mu \mathrm{A} \times 1$ coPyr $80 \mu \mathrm{A} \times 1 \quad$ iPyr $80 \mu \mathrm{A} \times 2 \quad$ coPyr $80 \mu \mathrm{A} \times 2$
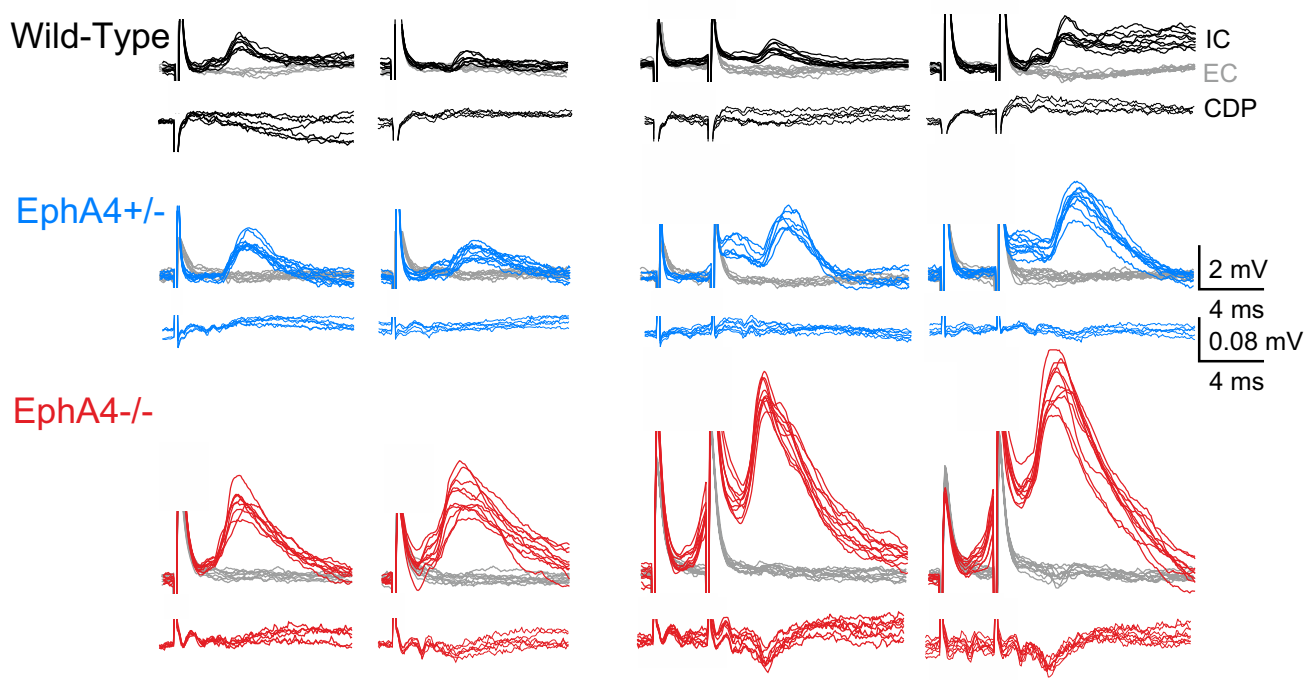

EphA4-/-

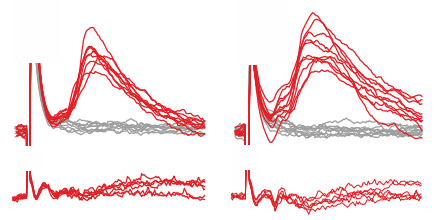

iPyr $40 \mu \mathrm{A} \times 1$ coPyr $40 \mu \mathrm{A} \times 1$
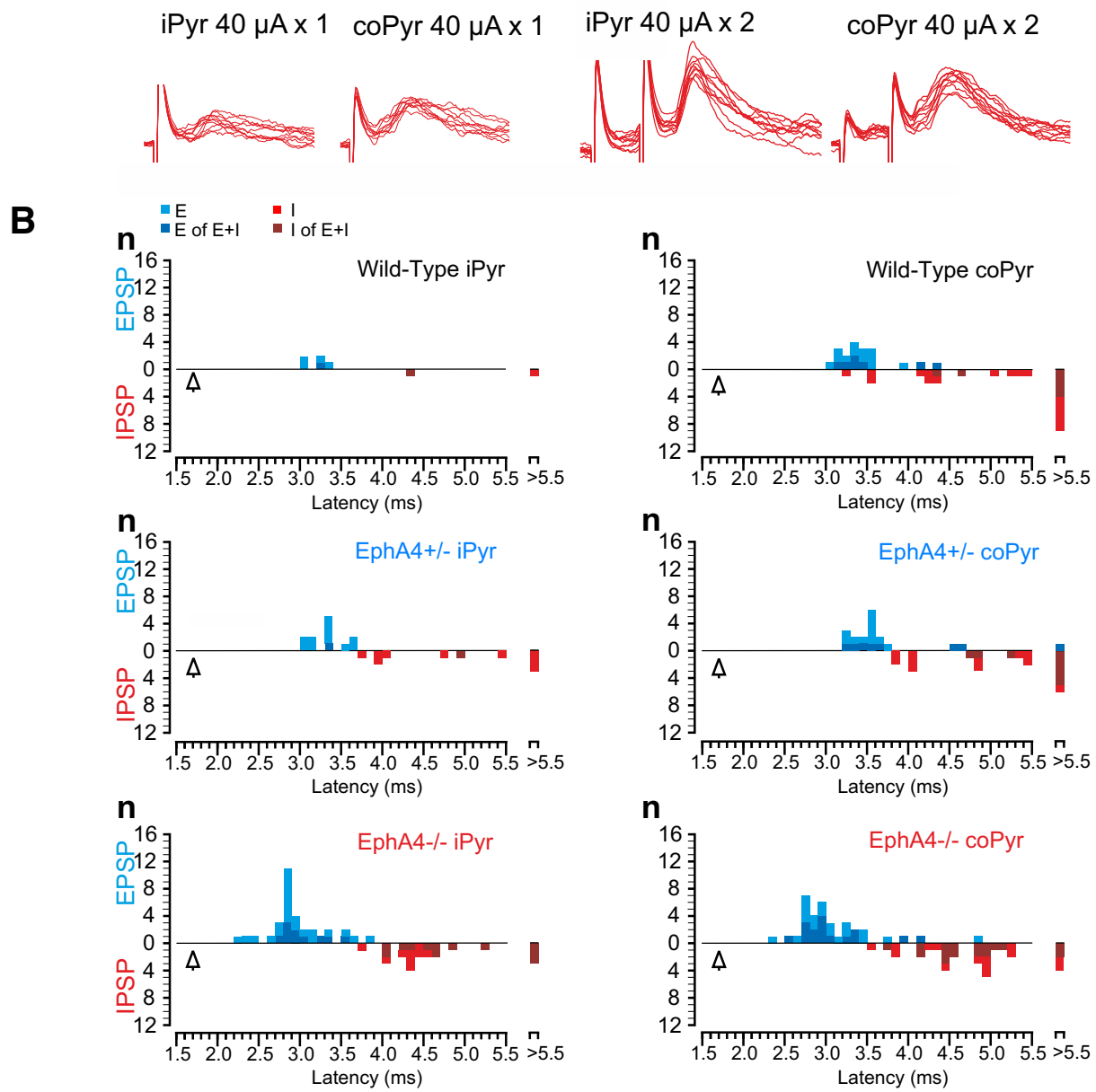

Figure 4. Corticospinal tract stimulation elicits increased excitation of forelimb motor neurons in EphA4 knock-out mice. A, Samples of EPSPs evoked by stimulation of ipsilateral and contralateral pyramids in forelimb motor neurons in wild-type (black), EphA4 ${ }^{+-}$(blue), and EphA4 ${ }^{-1-}$ (red) mice. IC, intracellular recordings; EC, extracellular recordings (gray lines); CDP, cord dorsum potential; $80 \mu \mathrm{A} \times 2$, stimulation intensity with a train of 2 stimuli at $80 \mu \mathrm{A}$. B. Segmental latencies of EPSPs and IPSPs in each group. Empty triangle shows the latency of the direct volley. E, EPSPS; I, IPSPS; E + I, mixed EPSPs and IPSPS.

Decreased direct propriospinal excitation on MNs in EphA4 knock-out mice

Cervical PNs receive feedforward commands from supraspinal motor pathways. They provide direct ipsilateral activation of
FMNs and of precerebellar neurons in the LRN. Thus, PNs are centrally located in conveying motor commands to MNs, and to provide internal feedback to LRN-cerebellar circuits during the control of skilled reaching (Azim et al., 2014). To investigate 
A

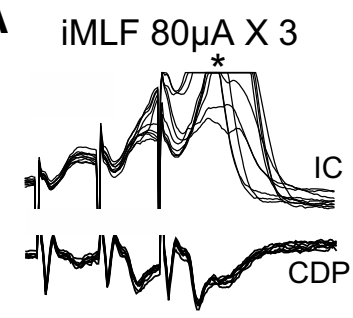

iPyr $80 \mu \mathrm{A} \times 3$

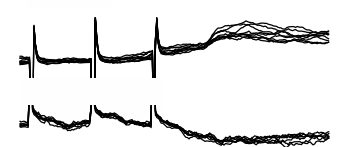

B
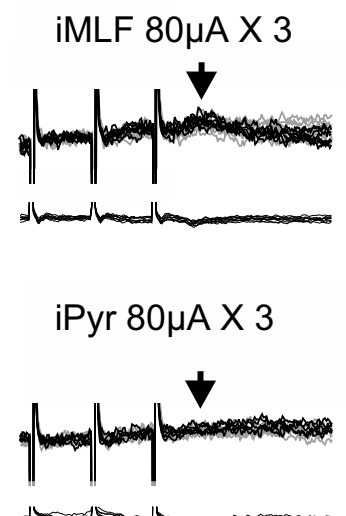

COMLF $80 \mu \mathrm{A} \times 3$
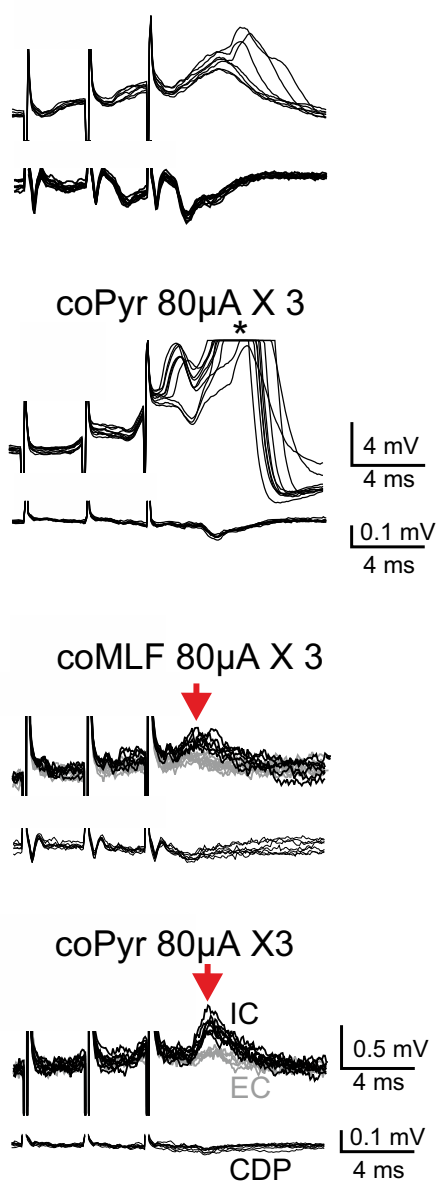

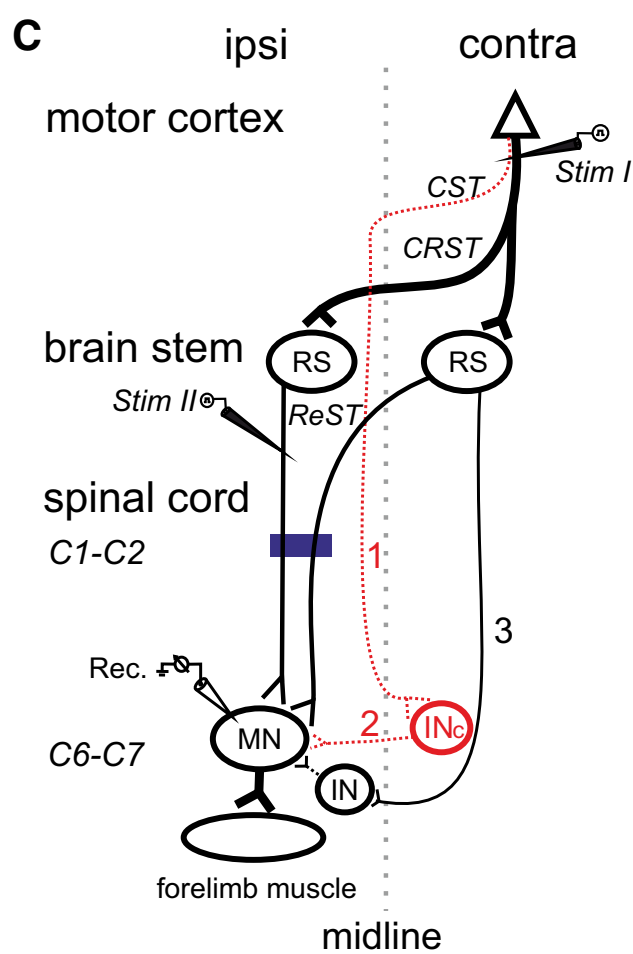

D

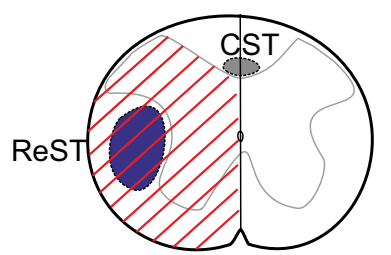

Figure 5. Cortical and reticulospinal excitation on forelimb motor neurons is drastically reduced after ipsilateral $\mathrm{C} 1 / \mathrm{C} 2$ hemisection sparing the dorsal column in EphA4 knock-out mice. $A$, Ipsilateral (ipsi) and contralateral (contra) cortical and reticulospinal excitation recorded from the same forelimb motor neuron before ipsilateral $\mathrm{C1} / \mathrm{C} 2$ hemisection sparing the dorsal column. $80 \mu \mathrm{A} \times 3$, stimulation intensity at $80 \mu \mathrm{A}$ with a train of 3 stimuli. *Spikes were clipped because of record limit $(10 \mathrm{mV})$. B. Ipsilateral and contralateral cortical and reticulospinal excitation recorded from the same forelimb motor neuron after ipsilateral C1/C2 hemisection sparing the dorsal column. Black arrows show that ipsilateral MLF and Pyr stimulation did not evoke EPSPS on MNs after the lesion. Red arrows indicate remaining coMLF and coPyr EPSPs after the lesion. IC, intracellular recordings; EC, extracellular recordings (gray lines); (DP, cord dorsum potential. C, Schematic outline of descending supraspinal motor pathways controlling skilled reaching in EphA4 ${ }^{-1-}$ mice. Note that only one side of stimulation is shown, although, in some experiments, the other side was used for stimulation. The red dashed lines show axonal misrouting of the CST (no. 1) and spinal interneurons (no. 2). The black line with the number 3 shows the contralateral ReST crossing at the midline in the caudal cervical spinal cord. RS, Reticulospinal neuron; INc, excitatory IN that aberrantly cross the midline. D, The dark blue block shows the ReST lesion by ipsilateral C1/C2 hemisection sparing the dorsal column. Stim I, Stimulation site in the coPyr; Stim II, stimulation site in the iMLF; Rec, record in the FMN. Note that stimulation in the iPyr or coMLF is not shown.

whether PN circuit dysfunction might be involved in impaired reaching in EphA4 knock-out mice, we explored the activation of MNs by PNs using in vivo intracellular recordings (Fig. 6). Stimulating the ascending PN axonal branch in the ipsilateral LRN to evoke antidromic PN stimulation elicited EPSPs, IPSPs, and mixed responses in FMNs (Jiang and Alstermark, 2015; Table 2). We focused on the occurrence of monosynaptic EPSPs in which the latencies measured from the direct volley were $<1.0 \mathrm{~ms}$, implying direct antidromic activation of excitatory PNs and their connections to MNs. Monosynaptic EPSPs were observed in 57.6\% (19 of 33) of MNs in wild-type and 48.3\% (14 of 29) of MNs in EphA4 $4^{+/}$mice. However, only 18.1\% (13 of 72) of MNs showed monosynaptic EPSPs in EphA4 ${ }^{-1-}$ mice (Fig. $6 C$ ), which is significantly fewer than in the other two groups $\left[\chi^{2}\right.$ test: $X^{2}(2, n=134)=18.9, p<0.0001$; wild-type vs $\mathrm{EphA}^{+/-}, X^{2}(1, n=62)=0.54, p=0.46$; wild-type vs EphA4 ${ }^{-/-}$, $X^{2}(1, n=105)=16.7, p<0.0001 ; \mathrm{EphA}^{+/-}$vs EphA4 ${ }^{-/-}, X^{2}(1$, $n=101)=9.6, p=0.002]$. These results indicate that lack of
EphA4 disturbs direct monosynaptic transmission of feedforward motor commands from PNs to FMNs.

Loss of EphA4 disrupts function of LRN-cerebellum internal feedback pathways implicated in the control of reaching The LRN receives predominantly PN inputs and sends all of its efferent axons to the cerebellum as mossy fibers that activate the granule cells as well as deep cerebellar nuclei. Thus, the PN-LRN pathway is thought to provide the cerebellum with an efference copy of motor commands sent to FMNs (Alstermark and Isa, 2012; Azim et al., 2014; Azim and Alstermark, 2015). We tested the integrity of the ascending LRN-cerebellar pathway in EphA4-null mutant mice. Bilateral surface recordings were performed with a silver ball electrode at 36 positions located in the bilateral posterior cerebellar cortex (Fig. 7A). As shown in Figure $7 C$, electrical stimulation in the left LRN at $100 \mu \mathrm{A}$ elicited a direct mossy fiber volley (N1) and a synaptic mossy fiber-granule cell volley (N2; Eccles et al., 1967). We analyzed and compared 
A

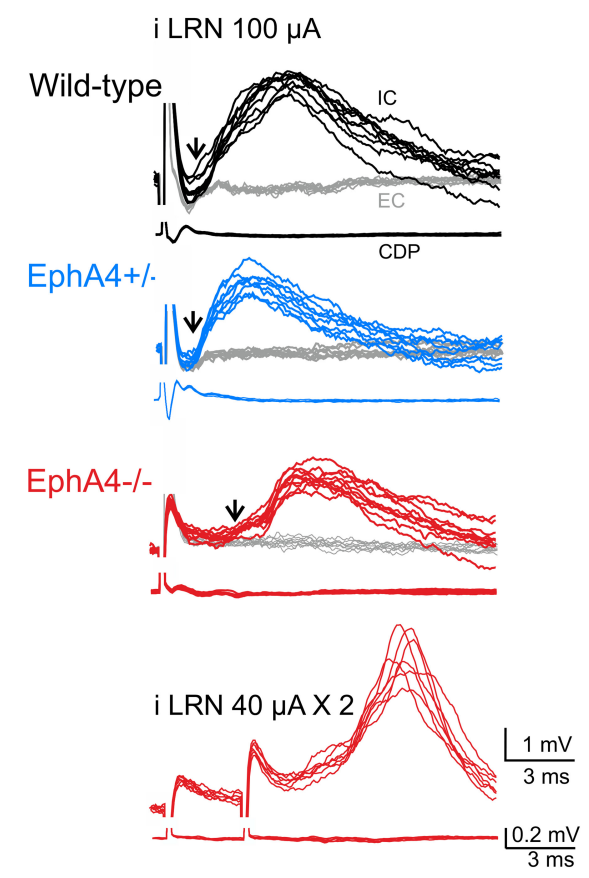

B
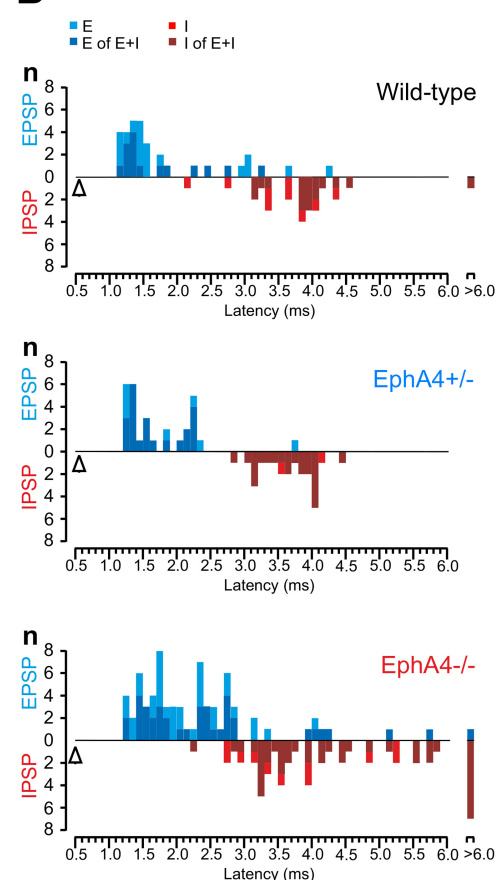

C

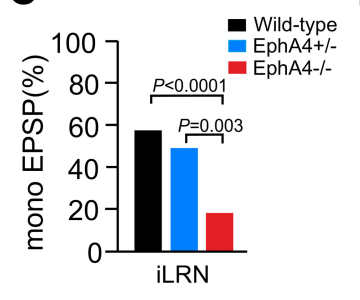

D

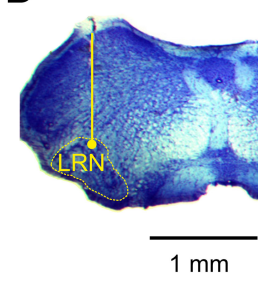

E

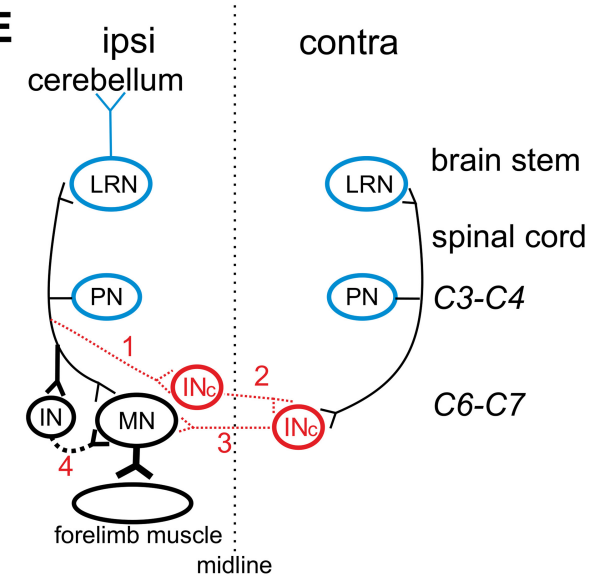

Figure 6. Direct excitation by propriospinal stimulation on forelimb motor neurons is decreased in EphA4 knock-out mice. A, Samples of EPSPs evoked by stimulation in the ipsilateral LRN in forelimb motor neurons in wild-type (black), EphA4 ${ }^{+/-}$(blue) and EphA4 ${ }^{-1-}$ (red) mice. Black arrow shows onset of EPSPs. IC, intracellular recordings; EC, extracellular recordings (gray lines). CDP, cord dorsum potential. $\boldsymbol{B}$, Segmental latencies of EPSPs and IPSPs in each group. Empty triangle shows the latency of direct volley. $\boldsymbol{C}$, Comparison of proportions of monosynaptic EPSPs in three groups of mice. $\chi^{2}$ test: $X^{2}(2, n=134)=18.9, p<0.0001$. $D, A$ transverse section shows LRN track for electrical stimulation. $E$, Schematic outline of direct and indirect PN-MN excitation in EphA4 ${ }^{-1-}$ mice. INc, Excitatory IN that aberrantly cross the midline; E, EPSPs; I, IPSPs; E + I, mixed EPSPs and IPSPs. The numbers 1, 2, and 3 show a PN - ipsilateral INc - contralateral INc - MN pathway. The number 4 shows an indirect PN-MN pathway via ipsilateral INs.

the peak amplitude of N1 and N2 recorded from three groups of mice. The results showed that the direct mossy fiber volley (N1) recorded from the medial positions (Fig. $7 \mathrm{~A}, \mathrm{Ai}, \mathrm{Bi}, \mathrm{Ci}$, and $\mathrm{Gi}$, red circles) was increased in EphA4 ${ }^{-1-}$ mice (Fig. $7 B$, two-way ANOVA: position A, $F_{(2,28)}=4.4, p=0.022$; position $\mathrm{B}, F_{(2,28)}=5.82$, $p=0.008$; position $\mathrm{D}, F_{(2,28)}=6.9, p=0.004$; position $\mathrm{G}, F_{(2,28)}=6.1$, $p=0.006)$. The significant difference was presented in ipsilateral $\mathrm{N} 1$ between EphA $4^{-1-}$ and EphA $4^{+/-}$mice (Fig. $7 B$, post hoc Bonferroni test, $p<0.05$ ), but not compared with wild-type mice. Moreover, comparison of the peak amplitude of N2 showed a large ipsilateral $\mathrm{N} 2$ and a relatively small contralateral N2 at three lateral positions (Fig. $7 A, D, E, F$, red squares) in wild-type and EphA4 $4^{+/-}$ mice. However, there was no significant difference between ipsilateral and contralateral $\mathrm{N} 2$ in EphA $4^{-1-}$ mice (Fig. $7 D$, paired $t$ test, position Di/Dc: wild-type, $p=0.02$; EphA4 ${ }^{+/-}, p=0.02$; EphA4 ${ }^{-/-}$, $p=0.14$; position Ei/Ec: wild-type, $p=0.002$; $\mathrm{EphA}^{+/-}, p=0.02$; EphA $4^{-1-}, p=0.15$; position Fi/Fc: wild-type, $p=0.04$; EphA $4^{+/-}$, $p=0.04 ;$ EphA4 $^{-1-}, p=0.42$; wild-type, $n=7 ; \mathrm{EphA}^{+/-}, n=5$; EphA4 $\left.{ }^{-/-}, n=5\right)$. These data suggest a functional perturbation of the ascending LRN-cerebellar pathway in EphA4-null mutant mice, which may then influence forelimb movement via descending command pathways.

Thus, the loss of EphA4 disrupts feedforward motor command pathways, as well as internal feedback loops that project through the cerebellum to update ongoing forelimb motor output.

\section{Discussion}

Here we demonstrate that a null mutation of EphA4 impairs the ability of mice to perform skilled reaching, which is associated with discrete neurophysiological changes in multiple feedforward and feedback pathways. EphA4 knock-out mice display impaired goal-directed reaching movements. The observed changes in the neural circuitry include an increased strength of the excitatory coupling mediated via CRST that underlies disynaptic and polysynaptic transmission of feedforward motor commands from neocortex to FMNs. Moreover, we identified reduced strength in monosynaptic excitatory connections transmitting feedforward motor commands from reticulospinal and propriospinal neurons to FMNs. In addition, lack of EphA4 compromises intrinsic cerebellar circuits involved in internal feedback mechanisms that support the control of reaching. We discuss the function of these motor pathways, and how they could be altered by the EphA4null mutation and result in impaired reaching.

\section{Alterations in corticofugal and reticulospinal excitation on FMNs cannot be explained by CST and in miswiring}

Loss of EphA4 causes CST and IN miswiring in cervical spinal cord, which is likely to disturb cortical excitation on FMNs. Here we found that indirect cortical excitation is increased whereas the direct reticulospinal excitation is decreased on FMNs in EphA $4^{-l-}$ mice. However, the ReST lesion experiments indicate that the abnormal CST and IN projections cannot explain the alteration of corticofugal and reticulospinal excitation of FMNs. First, there is no significant difference in reticulospinal excitation after the lesion in the three groups of mice. Second, only small contralateral corticofugal excitation remains after the lesion in EphA4 knock-out mice. These responses might be explained by CST and IN miswiring or might share the same mechanism as the remaining small coMLF after the lesion (Fig. 5C). Yet this 
A

\section{Cerebellum}

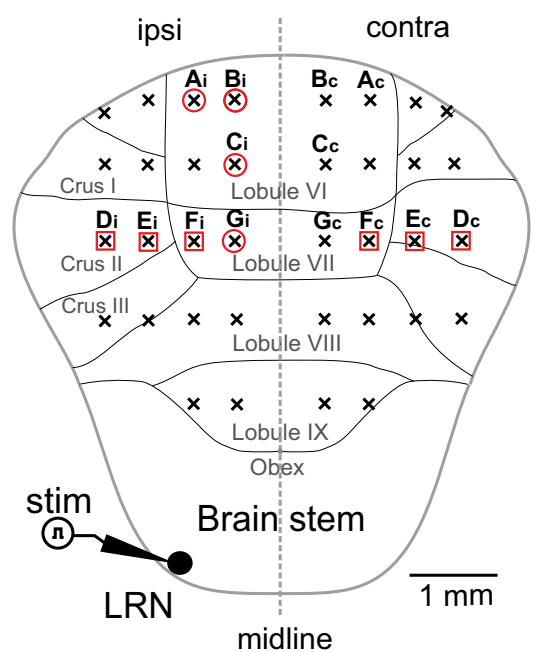

B
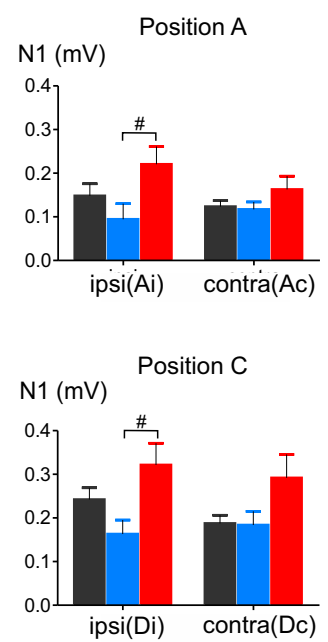

Wild-type

EphA4+/-

EphA4-/-

Position B
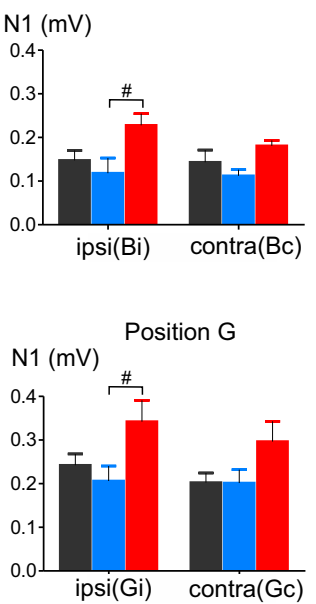

C

Position D ipsi(Di) contra(Dc)

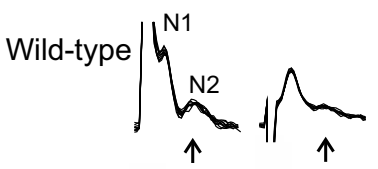

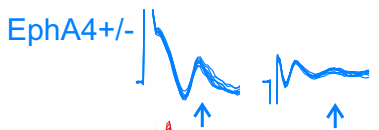

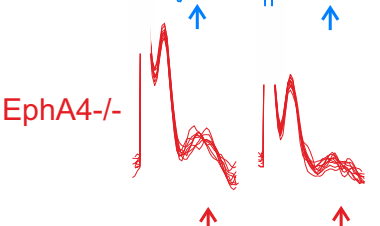

D

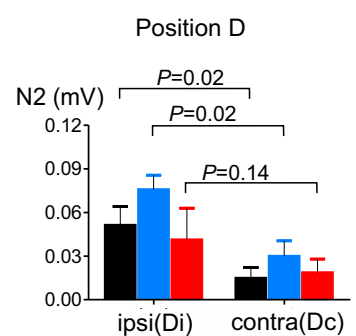

Position E ipsi(Ei) contra(Ec)

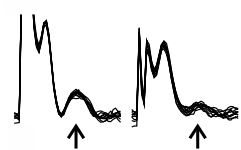

Position F ipsi(Fi) contra(Fc)

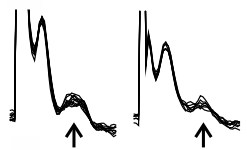

Position G

ipsi(Gi) contra(Gc)

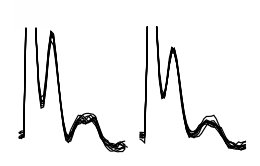

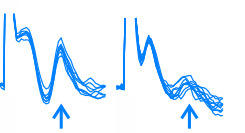

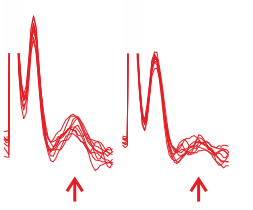

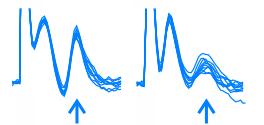

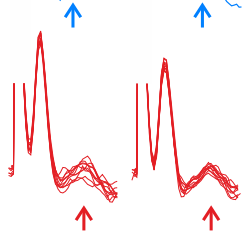

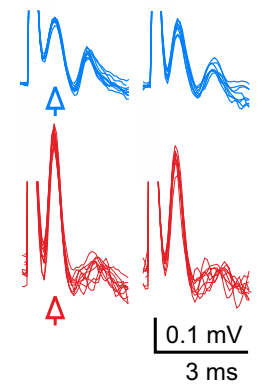

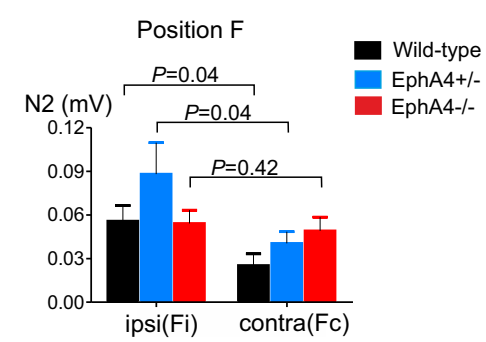

Figure 7. EphA4 knock-out mice show dysfunction in activation of ascending LRN-cerebellar pathway. $A$, Schematic drawing of surface recordings at 36 positions located in bilateral posterior cerebellar cortex combined with stimulation in the left LRN. Black crosses $(X)$ indicate recording positions. Red circles and squares indicate positions that show significant alterations in EphA4 ${ }^{-1-}$ mice. $B$, Comparison of the direct mossy fiber volley (N1) from three groups of mice shows that the peak amplitude of ipsilateral $\mathrm{N} 1$ was increased at the medial positions Ai, Bi, $\mathrm{C}$, and $\mathrm{Gi}$ (red circles in $\boldsymbol{A}$ ) in EphA4 ${ }^{-1-}$ mice. Two-way ANOVA: position $\mathrm{A}, F_{(2,28)}=4.366, p=0.022 ;$ position $\mathrm{B}, F_{(2,28)}=5.820, p=0.008$; position $\mathrm{D}, F_{(2,28)}=6.863, p=0.004 ;$ position $\mathrm{G}$, $F_{(2,28)}=6.103, p=0.006$. Post hoc Bonferroni test, \#p $<0.05$. C, Samples of the direct mossy fiber volley (N1) and the synaptic mossy fiber-granule cell volley (N2) recorded at ipsilateral positions $\mathrm{Di}, \mathrm{Ei}, \mathrm{Fi}, \mathrm{Gi}$, and contralateral positions $\mathrm{DC}, \mathrm{Ec}, \mathrm{Fc}$, and $\mathrm{Gc}$ from wild-type (black), EphA4 ${ }^{+/-}$(blue), and $\mathrm{EphA4}^{-/-}$(red) mice. Arrows indicate N2 that shows large ipsilateral N2 and small contralateral $\mathrm{N} 2$ at lateral positions $\mathrm{D}, \mathrm{E}$, and $\mathrm{F}$ in wild-type and $\mathrm{EphA4}^{+-}$mice, but not in EphA4 ${ }^{-1-}$ mice. Empty triangles indicate $\mathrm{N} 1$ that shows larger ipsilateral $\mathrm{N} 1$ at medial position $\mathrm{Gi}$ in $\mathrm{EphA4}^{-1-}$ mice (red) than one in EphA4 ${ }^{+/-}$mice (blue). D, Comparison of difference in the peak amplitude between ipsilateral and contralateral N2 at positions D, E, and F from wild-type (black), EphA4 ${ }^{+/-}$(blue), and EphA4 ${ }^{-l-}$ mice (red). Paired $t$ test, wild-type, $n=7 ; \mathrm{EphA4}^{+/-}, n=5 ; \mathrm{EphA4}^{-1-}, n=5$. contra, contralateral; ipsi, ipsilateral.

effect is very weak, suggesting that axonal misrouting of the CST and spinal INs has little influence on cortical excitation of FMNs.

However, we cannot rule out the role of CST misprojections in impaired reaching. We observed forelimb hopping during reaching in EphA4 $4^{-1-}$ mice, which is consistent with the findings in mice with conditional EphA4 gene ablation in the forebrain (Serradj et al., 2014; Serradj and Martin, 2016). The forebrain ablation of EphA4 produces abnormal CST projections 
but spares brainstem and spinal cord motor circuits. The conditional knock-out mice performed hopping in forelimb during adaptive locomotion and exploratory reaching, suggesting a selective involvement of the CST misrouting in forelimb hopping during reaching.

Neural plasticity in motor circuits controlling movements is an important mechanism for behavioral recovery and compensation after injuries (Jones, 2017). In this study, the enhancement of the corticoreticular synapse might be caused by reduction in reticulospinal excitation, which can be influenced by the PN-LRN-cerebellum-DCN-ReST system (Fig. 8). If so, homeostatic compensatory plasticity can establish a new balance between corticofugal and reticulospinal excitation of MNs (Alstermark and Pettersson, 2014a). Indeed, analysis of the size of EPSPs in the same MNs shows that MNs with relatively small iPyr EPSPs, but large coPyr EPSPs conversely display large iMLF EPSPs but small coMLF EPSPs in EphA4 ${ }^{-1-}$ mice (Fig. $5 A$ ). Furthermore, EphA4 ${ }^{-/-}$mice showed an improvement in performing the position 1 test with an increase of the training times (Fig. 1C). We reason that the functional compensation between CRST and ReST pathways in the neural circuits controlling reaching in the low demand task may in part be responsible for preserving skilled reaching behavior. However, in a high-demand task such as the liftingprotraction test, the CST may be recruited for modulation of sensory-motor integration. Thus, activation of strong bilateral CST spinal projections could explain the observed mirror movements in forelimb and impair reaching.

\section{Aberrant spinal in projections may disturb direct PN-MN excitation}

Cervical PNs play pivotal roles in conveying motor commands to FMNs and also in providing internal feedback control for skilled reaching (Azim et al., 2014). Our work demonstrates that the proportion of monosynaptic EPSPs from PNs to FMNs is decreased in EphA4 $4^{-1-}$ mice, indicating weak direct PN-MN excitation. One possibility for the long latencies of the EPSPs might be slow conduction velocity in PN axons. However, we exclude this possibility because we could still evoke some EPSPs within the monosynaptic range in EphA4 $4^{-1-}$ mice (Fig. $6 B$, bottom). A more likely explanation is that an axonal misrouting of spinal interneuronal connections disrupts the direct PN-MN excitation. It was reported that the ipsilateral excitatory V2a PN class do not cross the midline in EphA4 knock-out mice (Lundfald et al., 2007). If so, some other excitatory spinal INs that normally project ipsilaterally may aberrantly cross the midline as a result of the EphA4-null mutation (Kullander et al., 2003; Satoh et al., 2016). The nonmonosynaptic EPSPs from PNs to MNs could be mediated via ipsilateral INs (Fig. 6E, no. 4), which is similar as in control mice. The polysynaptic EPSPs might be mediated via a $\mathrm{PN}-$ ipsilateral IN-contralateral IN-MN pathway (Fig. 6E, nos. $1,2,3)$. Indeed, stimulation of contralateral PNs can evoke dominant disynaptic EPSPs but not monosynaptic EPSPs in FMNs in EphA $4^{-l-}$ mice (data not shown). The disynaptic EPSPs are possibly mediated by the activation of contralateral INs that aberrantly cross the midline and then project to ipsilateral MNs (Fig. $6 E$, no. 3). Thus, abnormal interneuronal connectivity following lack of EphA4 may cause a disturbance in direct propriospinal excitation on FMNs.

Different spinal INs are involved in different aspects of limb behavior. C3-C4 PNs mediate the command for reaching, and C6-C7 segmental INs are required for grasping in the cat (Alstermark and Isa, 2012). Ablation of cervical V2a Chx10 ${ }^{+}$INs perturbs reaching in mice (Azim et al., 2014), while dI3 INs is involved in grasping (Bui et al., 2013). Corticospinal neurons in motor cortex control reaching via spinal $\mathrm{Chx} 10^{+} \mathrm{INs}$, whereas corticospinal neurons in sensory cortex control food release via spinal Vglut $3^{+}$INs (Ueno et al., 2018). Our behavioral results show that lack of EphA4 mainly impaired reaching, but not grasping, suggesting that axonal misrouting of spinal INs mainly disturb the function of PNs in EphA $4^{-1-}$ mice.

\section{Effect of EphA4-null mutation on the LRN-cerebellum internal feedback pathway}

One deficit in reaching observed in EphA4 ${ }^{-1-}$ mice was hypometria (Fig. 1B,C). The animals undershot the aimed target, therefore causing impaired reaching. Hypometria, as well as hypermetria, is thought to be a major sign of cerebellar dysfunctions (Manto, 2009). EphA4 receptors are observed in the cerebellum (Rogers et al., 1999; Greferath et al., 2002) and are involved in chick cerebellar development (Karam et al., 2000). But the development of Purkinje cells and granule cells seems not to be affected in EphA4-null mutant mice (Karam et al., 2002). EphA4 controls the development of olivocerebellar projections and EphA4 deficit mice show axon misrouting of inferior olivary neurons (Hashimoto et al., 2012), which may also affect behavioral performance.

Here, we observe weak alterations in the incoming mossy fiber volley in EphA4 $4^{-1-}$ mice, suggesting that the number of mossy fibers that project to the cerebellum from the LRN might be increased in the medial part of cerebellar surface, which covers a cerebellar cortical area known to be involved in the control 
of posture and locomotion. On the other hand, the synaptic responses induced by mossy fiber-granule cell volley, which indicates the synaptic strength of LRN-granule cell connections, was functionally changed in the lateral part of cerebellar surface, which covers cerebellar cortical areas controlling forelimb movements (Ito, 1984). While it is not yet fully understood how synaptic strength is changed in the LRN-cerebellar pathway in mice lacking EphA4, the present results support a model in which defects in reaching may in part be because of a functional change in the LRN-cerebellum internal feedback pathway, which in turn will cause altered activation of reticulospinal neurons that recruit spinal MNs.

In conclusion, our findings provide direct in vivo evidence at the circuit level establishing how feedforward and feedback forelimb motor circuits controlling skilled reaching are functionally disrupted by loss of EphA4 gene. The abnormal activities in multiple motor pathways controlling FMNs could result from changes in synaptic strength and/or in the number of neurons recruited by aberrant circuit connectivity. We propose one most likely possibility (Fig. 8). Axonal misrouting of spinal INs (no. 2) disturbs the unilateral direct $\mathrm{PN}-\mathrm{MN}$ activation (no. 5). In addition, axonal misrouting disrupts the normal function of the ascending PN-LRN-cerebellum system (no. 6). This may in turn disturb monosynaptic reticulospinal excitation (no. 4) and then, by homeostatic plasticity, in an increase of cortico-reticulo-spinal excitation to FMNs (no. 3). Together, these effects lead to deficits in reaching in EphA4 knock-out mice. This functional analysis of neural circuit controlling movements may help to understand the pathophysiological mechanisms underlying human movement disorders, such as mirror disorders that are unable to perform asymmetric skilled hand movements (Yokoyama et al., 2001).

\section{References}

Akay T, Acharya HJ, Fouad K, Pearson KG (2006) Behavioral and electromyographic characterization of mice lacking EphA4 receptors. J Neurophysiol 96:642-651.

Alstermark B, Isa T (2012) Circuits for skilled reaching and grasping. Annu Rev Neurosci 35:559-578.

Alstermark B, Ogawa J (2004) In vivo recordings of bulbospinal excitation in adult mouse forelimb motoneurons. J Neurophysiol 92:1958-1962.

Alstermark B, Pettersson LG (2014a) Endogenous plasticity in neuro-rehabilitation following partial spinal cord lesions. Front Neurosci 8:59.

Alstermark B, Pettersson LG (2014b) Skilled reaching and grasping in the rat: lacking effect of corticospinal lesion. Front Neurol 5:103.

Alstermark B, Lindström S, Lundberg A, Sybirska E (1981) Integration in descending motor pathways controlling the forelimb in the cat. 8 . Ascending projection to the lateral reticular nucleus from $\mathrm{C} 3-\mathrm{C} 4$ propriospinal also projecting to forelimb motoneurones. Exp Brain Res 42:282298.

Alstermark B, Kümmel H, Pinter MJ, Tantisira B (1990) Integration in descending motor pathways controlling the forelimb in the cat. 17. Axonal projection and termination of $\mathrm{C} 3-\mathrm{C} 4$ propriospinal neurones in the C6Th1 segments. Exp Brain Res 81:447-461.

Auclair F, Marchand R, Glover JC (1999) Regional patterning of reticulospinal and vestibulospinal neurons in the hindbrain of mouse and rat embryos. J Comp Neurol 411:288-300.

Azim E, Alstermark B (2015) Skilled forelimb movements and internal copy motor circuits. Curr Opin Neurobiol 33:16-24.

Azim E, Jiang J, Alstermark B, Jessell TM (2014) Skilled reaching relies on a V2a propriospinal internal copy circuit. Nature 508:357-363.

Borgius L, Nishimaru H, Caldeira V, Kunugise Y, Löw P, Reig R, Itohara S, Iwasato T, Kiehn O (2014) Spinal glutamatergic neurons defined by EphA4 signaling are essential components of normal locomotor circuits. J Neurosci 34:3841-3853.
Brösamle C, Schwab ME (1997) Cells of origin, course, and termination patterns of the ventral, uncrossed component of the mature rat corticospinal tract. J Comp Neurol 386:293-303.

Bui TV, Akay T, Loubani O, Hnasko TS, Jessell TM, Brownstone RM (2013) Circuits for grasping: spinal $\mathrm{dI} 3$ interneurons mediate cutaneous control of motor behavior. Neuron 78:191-204.

Butt SJ, Lundfald L, Kiehn O (2005) EphA4 defines a class of excitatory locomotor-related interneurons. Proc Natl Acad Sci U S A 102:14098-14103.

Canty AJ, Greferath U, Turnley AM, Murphy M (2006) Eph tyrosine kinase receptor EphA4 is required for the topographic mapping of the corticospinal tract. Proc Natl Acad Sci U S A 103:15629-15634.

Coonan JR, Greferath U, Messenger J, Hartley L, Murphy M, Boyd AW, Dottori M, Galea MP, Bartlett PF (2001) Development and reorganization of corticospinal projections in EphA4 deficient mice. J Comp Neurol 436:248-262.

Dottori M, Hartley L, Galea M, Paxinos G, Polizzotto M, Kilpatrick T, Bartlett PF, Murphy M, Köntgen F, Boyd AW (1998) EphA4 (Sek1) receptor tyrosine kinase is required for the development of the corticospinal tract. Proc Natl Acad Sci U S A 95:13248-13253.

Eccles JC, Ito M, Szentagothai J (1967) The cerebellum as a neuronal machine. Berlin: Springer.

Flanagan JG, Vanderhaeghen P (1998) The ephrins and Eph receptors in neural development. Annu Rev Neurosci 21:309-345.

Greferath U, Canty AJ, Messenger J, Murphy M (2002) Developmental expression of EphA4-tyrosine kinase receptor in the mouse brain and spinal cord. Mechanisms of development 119 [Suppl 1]1:S231S238.

Hashimoto M, Ito R, Kitamura N, Namba K, Hisano Y (2012) Epha4 controls the midline crossing and contralateral axonal projections of inferior olive neurons. J Comp Neurol 520:1702-1720.

Henkemeyer M, Orioli D, Henderson JT, Saxton TM, Roder J, Pawson T, Klein R (1996) Nuk controls pathfinding of commissural axons in the mammalian central nervous system. Cell 86:35-46.

Illert M, Lundberg A, Tanaka R (1977) Integration in descending motor pathways controlling the forelimb in the cat. 3. Convergence on propriospinal neurones transmitting disynaptic excitation from the corticospinal tract and other descending tracts. Exp Brain Res 29:323-346.

Ito M (1984) The cerebellum and neural control. New York: Raven.

Jiang J, Alstermark B (2015) Not GABA but glycine mediates segmental, propriospinal, and bulbospinal postsynaptic inhibition in adult mouse spinal forelimb motor neurons. J Neurosci 35:1991-1998.

Jones TA (2017) Motor compensation and its effects on neural reorganization after stroke. Nat Rev Neurosci 18:267-280.

Karam SD, Burrows RC, Logan C, Koblar S, Pasquale EB, Bothwell M (2000) Eph receptors and ephrins in the developing chick cerebellum: relationship to sagittal patterning and granule cell migration. J Neurosci 20:6488-6500.

Karam SD, Dottori M, Ogawa K, Henderson JT, Boyd AW, Pasquale EB, Bothwell M (2002) EphA4 is not required for Purkinje cell compartmentation. Brain research Developmental brain research 135:29-38.

Kullander K, Mather NK, Diella F, Dottori M, Boyd AW, Klein R (2001) Kinase-dependent and kinase-independent functions of EphA4 receptors in major axon tract formation in vivo. Neuron 29:73-84.

Kullander K, Butt SJ, Lebret JM, Lundfald L, Restrepo CE, Rydström A, Klein R, Kiehn O (2003) Role of EphA4 and EphrinB3 in local neuronal circuits that control walking. Science 299:1889-1892.

Lemon RN (2008) Descending pathways in motor control. Annu Rev Neurosci 31:195-218.

Lundfald L, Restrepo CE, Butt SJ, Peng CY, Droho S, Endo T, Zeilhofer HU, Sharma K, Kiehn O (2007) Phenotype of V2-derived interneurons and their relationship to the axon guidance molecule EphA4 in the developing mouse spinal cord. Eur J Neurosci 26:2989-3002.

Manto M (2009) Mechanisms of human cerebellar dysmetria: experimental evidence and current conceptual bases. J Neuroeng Rehabil 6:10.

O'Leary DD, Wilkinson DG (1999) Eph receptors and ephrins in neural development. Curr Opin Neurobiol 9:65-73.

Pasquale EB (2008) Eph-ephrin bidirectional signaling in physiology and disease. Cell 133:38-52.

Pivetta C, Esposito MS, Sigrist M, Arber S (2014) Motor-circuit communication matrix from spinal cord to brainstem neurons revealed by developmental origin. Cell 156:537-548. 
Restrepo C, Margaryan G, Borgius L, Lundfald L, Sargsyan D, Kiehn O (2011) Change in the balance of excitatory and inhibitory midline fiber crossing as an explanation for the hopping phenotype in EphA4 knockout mice. Eur J Neurosci 34:1102-1112.

Rogers JH, Ciossek T, Menzel P, Pasquale EB (1999) Eph receptors and ephrins demarcate cerebellar lobules before and during their formation. Mech Dev 87:119-128.

Satoh D, Pudenz C, Arber S (2016) Context-dependent gait choice elicited by EphA4 mutation in Lbx1 spinal interneurons. Neuron 89:1046-1058.

Serradj N, Martin JH (2016) Motor experience reprograms development of a genetically-altered bilateral corticospinal motor circuit. PLoS One 11: e0163775.

Serradj N, Paixão S, Sobocki T, Feinberg M, Klein R, Kullander K, Martin JH (2014) EphA4-mediated ipsilateral corticospinal tract misprojections are necessary for bilateral voluntary movements but not bilateral stereotypic locomotion. J Neurosci 34:5211-5221.
Ueno M, Nakamura Y, Li J, Gu Z, Niehaus J, Maezawa M, Crone SA Goulding M, Baccei ML, Yoshida Y (2018) Corticospinal circuits from the sensory and motor cortices differentially regulate skilled movements through distinct spinal interneurons. Cell Rep 23: 1286-1300.e7.

Watson C, Harrison M (2012) The location of the major ascending and descending spinal cord tracts in all spinal cord segments in the mouse: actual and extrapolated. Anat Rec (Hoboken) ) 295:1692-1697.

Wegmeyer H, Egea J, Rabe N, Gezelius H, Filosa A, Enjin A, Varoqueaux F, Deininger K, Schnütgen F, Brose N, Klein R, Kullander K, Betz A (2007) EphA4-dependent axon guidance is mediated by the RacGAP alpha2-chimaerin. Neuron 55:756-767.

Yokoyama N, Romero MI, Cowan CA, Galvan P, Helmbacher F, Charnay P, Parada LF, Henkemeyer M (2001) Forward signaling mediated by ephrin-B3 prevents contralateral corticospinal axons from recrossing the spinal cord midline. Neuron 29:85-97. 